\title{
Sources of Eddy Kinetic Energy in the Labrador Sea
}

\author{
CARsten Eden* and Claus Böning \\ Institut für Meereskunde, Universität Kiel, Kiel, Germany
}

(Manuscript received 16 July 2001, in final form 2 May 2002)

\begin{abstract}
Experiments with a suite of North Atlantic general circulation models are used to examine the sources of eddy kinetic energy (EKE) in the Labrador Sea. A high-resolution model version $\left(1 / 12^{\circ}\right)$ quantitatively reproduces the observed signature. A particular feature of the EKE in the Labrador Sea is its pronounced seasonal cycle, with a maximum intensity in early winter, as already found in earlier studies based on altimeter data. In contrast to a previously advanced hypothesis, the seasonally varying eddy field is not related to a forcing by highfrequency wind variations but can be explained by a seasonally modulated instability of the West Greenland Current (WGC). The main source of EKE in the Labrador Sea is an energy transfer due to Reynolds interaction work (barotropic instability) in a confined region near Cape Desolation where the WGC adjusts to a change in the topographic slope: Geostrophic contours tend to converge upstream of Cape Desolation, such that the topographically guided WGC narrows as well and becomes barotropically unstable. The eddies spawned from the WGC instability area, dominating the EKE in the interior Labrador Sea, are predominantly anticyclonic with warm and saline cores in the upper kilometer of the water column, while the few cyclones originating as well from the instability area show a more depth-independent structure. Companion experiments with a $13^{\circ}$ model exhibit the strength of the WGC, influenced by either changes in the wind stress or heat flux forcing, as a leading factor determining seasonal to interannual changes of EKE in the Labrador Sea.
\end{abstract}

\section{Introduction}

Satellite altimeter measurements have indicated a pronounced annual signal in the near-surface mesoscale eddy variability over some areas of the subpolar North Atlantic (White and Heywood 1995; Stammer and Wunsch 1999). An eddy signal exhibiting both a relatively high annual mean and a strong seasonality, with a maximum in late winter and an annual amplitude nearly as large as the annual average, was found in the Labrador Sea, particularly along a wedge of the West Greenland Current (WGC) branching off the continental slope near $61^{\circ}-62^{\circ} \mathrm{N}$. Several recent studies have described aspects of the eddy variability in the Labrador Sea in greater detail, based on surface drifters (Cuny et al. 2002; Fratantoni 2001), satellite altimetry and profiling RAFOS floats (Prater 2002), moored current meter observations (Lilly et al. 2002, manuscript submitted to J. Phys. Oceanogr., hereafter LRS), and a combination of the above (Brandt et al. 2002, manuscript submitted to J. Geophys. Res., hereafter BMS). In this study the question of the sources of the seasonally varying eddy

\footnotetext{
* Current affiliation: Department of Oceanography, Dalhousie University, Halifax, Nova Scotia, Canada.

Corresponding author address: Carsten Eden, Department of Oceanography, Dalhousie University, Halifax, NS B3H 4J1, Canada. E-mail: ceden@phys.ocean.dal.ca
}

signal in the Labrador Sea is addressed by examining model simulations.

Understanding the dynamical sources of the mesoscale variability in the Labrador Sea is important since the Atlantic Ocean's thermohaline circulation and its attendant northward heat transport appears to be particularly sensitive to the ventilation of the Labrador Sea (Häkkinen 1999; Eden and Willebrand 2001). This part of the world is one of the few regions in which deep wintertime convection takes place (Lazier 1973) and eddy activity is thought to be an integral part of the convection process and the formation of new Labrador Sea Water, through its role in the detrainment of the newly formed dense water from the deep, wintertime convection patches (Marshall and Schott 1999).

The pronounced seasonality of EKE over parts of the subpolar North Atlantic, especially over the offshore branches of the West Greenland Current, with a peak typically a few weeks after the annual (winter) maximum in the synoptic wind stress variability, was suggested to be indicative of a significant, local generation of eddies by fluctuating wind fields (White and Heywood 1995). Obviously, such a "directly" forced EKE signal should be subject to a corresponding seasonal modulation. Indications of a seasonality in EKE, albeit with amplitudes of only a few centimeters squared per second squared, were also detected in deep current meter records from the northeastern Atlantic (Dickson et al. 
1982) and Pacific Oceans (Koblinsky et al. 1989). However, this "direct" mechanism of the generation of mesoscale eddies, pioneered by Frankignoul and Müller (1979) and Müller and Frankignoul (1981), competes in a sense with the energy transfers due to hydrodynamical instabilities of the large-scale flow field driven by the mean atmospheric forcing. The effectiveness of the former, "direct" generation of eddies in the ocean has been under debate since the picture of the global EKE distribution, advanced on the basis of altimeter data, indicates a close association with the mean flow field over most regions of the mid latitude oceans, supporting the hypothesis of hydrodynamical instability mechanisms as the primary source of the mesoscale eddy fields (e.g., Stammer 1997). In addition, the ocean's response to high-frequency winds should predominantly be barotropic (Willebrand et al. 1980); hence, a significant contribution to the observed surface energy levels in the ocean by the direct generation mechanism is difficult to reconcile.

Ocean general circulation model (OGCM) simulations may help to assess the relative importance of the direct eddy generation and the role of instabilities of the large-scale currents. An almost depth-independent response to forcing with daily wind stress fields with amplitudes of a few centimeters squared per second squared, comparable with the deep current meter observations, was simulated with a medium-resolution $\left(1 / 3^{\circ}\right)$ OGCM (Stammer et al. 2001, hereafter SBD). Because of its small amplitude, this seasonally varying signal is detectable only in regions with a very weak background EKE, that is, away from the baroclinically unstable branches of the North Atlantic Current (NAC). The model study by SBD, however, lacked in horizontal resolution to resolve the small, less than $10 \mathrm{~km}$, Rossby radii in the subarctic Atlantic, necessary to quantitatively capture the hydrodynamical instability processes of the mean flow in that area.

The present study complements that of SBD in the sense that we are using an OGCM of the North Atlantic with much refined mesh size of $1 / 12^{\circ}$, but exclude the impact of high-frequency wind fluctuations. In our model experiments, we are not concerned with seasonally varying eddy generation by fluctuating winds, but with the seasonal cycle in the EKE solely driven by internal instability mechanisms. We will show that the model exhibits EKE patterns with a magnitude and seasonal cycle very similar to the signatures deduced from observations in the Labrador Sea.

We will then focus on the question of the nature of the hydrodynamic instabilities in the Labrador Sea. The generation of mesoscale eddies by the baroclinic instability of a geostrophically balanced "rim" current around a convective patch of newly formed dense water is thought to be a major agent for the detrainment of the ventilated water masses and the restratification of the region after convection (Marshall and Schott 1999). However, a difficulty in quantifying the impact of "con- vectively" generated eddies lies in the only fragmentary observation of eddies at the margin of the mixed regime (e.g., Clarke and Gascard 1983). On the other hand, instabilities of the boundary currents propagating into the interior Labrador Sea, may mask the signal of the "convectively" generated eddies and may overrule their impact on the restratification process. In fact, in a recent study (BMS), no conclusive evidence for a signal of "convectively" generated eddies could be found in either satellite altimeter data or surface drifters in the Labrador Sea. Thus, it appears unclear to what extent the instability of the rim current acts as an important source of EKE in the Labrador Sea and, in the presence of the only fragmentary observations, realistic model simulation may help to answer this question.

However, BMS found in altimeter data a remarkable increase in the level of EKE in the Labrador Sea in $1996 / 97$, accompanied by a general increase in basinscale sea level over the Labrador Sea (Reverdin et al. 1999; Esselborn and Eden 2001), related to the North Atlantic Oscillation (NAO). The present model results will shed light on possible factors in the atmospheric forcing that may lead to interannual changes in EKE and thus restratification in the Labrador Sea.

After a description of the modeling strategy in the next section, the model results with respect to the distribution and seasonality of the EKE in the Labrador Sea are discussed in section 3 , followed by an examination of the sources of EKE and the factors controlling interannual changes of EKE in the Labrador Sea in section 4; a summary and discussion of the model results is given in section 5 .

\section{Experimental setup}

The general circulation model is based on a refined configuration (Redler et al. 1998) of the Geophysical Fluid Dynamics Laboratory (GFDL) MOM2.1 code (Pacanowski 1995), developed as part of a hierarchy of Atlantic Ocean models [A family of linked Atlantic Ocean model experiments (FLAME); Dengg et al. (1999); see also http://www.ifm.uni-kiel.de/fb/fb1/tm/ research/FLAME/index.html]. This study draws from simulations with model versions using a domain spanning the North and Equatorial Atlantic between $18^{\circ} \mathrm{S}$ and $70^{\circ} \mathrm{N}$, similar as in the Dynamics of North Atlantic Models (DYNAMO) intercomparison exercise (Willebrand et al. 2001), as part of which SBD examined the seasonal cycle of EKE due to daily wind forcing. For the model experiments considered here, the wind and thermohaline forcing is based on the same monthly mean climatology of the European Centre for MediumRange Forecasts (ECMWF) analyses as used for DYNAMO; the same holds for the boundary conditions adopted for the open ocean, southern and northern limits of the domain [for details we refer to Willebrand et al. (2001) and references therein].

Our main emphasis is on a model version with a grid 
size of $1 / 12$ in longitude and $1 / 12{ }^{\circ} \cos \phi$ in latitude, yielding a mesh of about $5 \mathrm{~km} \times 5 \mathrm{~km}$ over the area of interest here. The cause of the seasonality in the modeled EKE will be elucidated further by case studies building on modifications in the atmospheric forcing; for computational reasons these are using a coarser grid of $1 / 3^{\circ}$, that is, the same as in DYNAMO. Note that configuration and forcing of both models are the same, except for horizontal resolution and (horizontal) subgrid-scale parameterizations (see below). Both model versions use 45 levels in the vertical, with a $10-\mathrm{m}$ resolution at the top.

The $1 / 12{ }^{\circ}$ model was initialized with velocity, temperature and salinity fields taken from the end of the (15 years long) spinup phase of the $1 / 3^{\circ}$ model, linearly interpolated on the grid of the $1 / 12{ }^{\circ}$ model..$^{1}$ Two different experiments with the $1 / 12{ }^{\circ}$ will be discussed, differing in the lateral subgrid-scale parameterization. While for the marginally eddy-resolving (or "eddy-permitting") $13^{\circ}$ model the usual practice of a biharmonic mixing was adopted in order to minimize the frictional damping on scales larger than the grid scale, the parameterization in the $1 / 12$ model was based on Laplacian horizontal mixing. In addition, we will briefly discuss in sections 3 and 5 results from a preliminary $1 / 12$ model case utilizing biharmonic mixing, similar as in the $1 / 10^{\circ}$ model study of Smith et al. (2000). ${ }^{2}$

In all our experiments the vertical diffusivity $K_{v}$ was set inversely proportional to the static stability $N$ of the water column $\left(K_{v}=10^{-3} \mathrm{~cm}^{2} \mathrm{~s}^{-2} \mathrm{~N}^{-1}\right)$ after Cummins et al. (1990) and Gargett (1984) to account for mixing by internal waves, which is believed to be more effective in case of weak stratification. Here, $K_{v}$ is bounded by minimal and maximal values of 0.1 and $4 \mathrm{~cm}^{2} \mathrm{~s}^{-1}$ for numerical reasons. Viscosity $A_{v}$ is treated in the same manner with $A_{v}=10^{-2} \mathrm{~cm}^{2} \mathrm{~s}^{-2} \mathrm{~N}^{-1}$, bounded by 2 and $10 \mathrm{~cm}^{2} \mathrm{~s}^{-1}$. (However, the momentum between the three uppermost levels, each about $10 \mathrm{~m}$ thick, is mixed constantly with a viscosity of $50 \mathrm{~cm}^{2} \mathrm{~s}^{-1}$ to account for the impact of wind stirring.)

We will discuss three different experiments with the $1 / 3^{\circ}$ model, each following a 15 -yr spinup phase: in experiment STANDARD-3, the $1 / 3^{\circ}$ model was integrated further on with the full seasonality in all fluxes; in experiment CONSTWIND-3, the $1 / 3^{\circ}$ model was forced with the annual mean wind stress; and in experiment CONSTHEATWIND-3, the $1 / 3^{\circ}$ model was forced with

\footnotetext{
${ }^{1}$ Every fourth grid point of the $1 / 12$ grid in both lateral directions coincides with the $1 / 3^{\circ}$ mesh; however, note that the topography in the $1 / 12{ }^{\circ}$ model, taken from the ETOPO2 dataset (Smith and Sandwell 1997), is not interpolated from the $1 / 3^{\circ}$ model.

${ }^{2}$ This case is not pursued further because of a model error near the open southern boundary at $18^{\circ} \mathrm{S}$ : a stable integration could only be obtained by using a "sponge layer" (extending to about $5^{\circ} \mathrm{S}$ ) with high friction near the southern boundary. While for this reason we choose not to discuss this experiment in detail, we will refer to some aspects of its EKE pattern under the assumption that the error does not affect the results in the Labrador Sea.
}

the annual mean wind stress and annual mean apparent atmospheric temperature and damping coefficient in the surface heat flux boundary condition (Barnier et al. 1995).

In the course of the integration of the $1 / 12$ model, two different sets of coefficients for viscosity and diffusivity were adopted: during a first, 3-yr-long "viscous" phase (VISCOUS-12), starting from the spinup of the $13^{\circ}$ model, the coefficients of the $1 / 12$ model were chosen such as to yield a similar damping timescale on the grid scale of the $1 / 3^{\circ}$ model. For a subsequent, 5 -yr-long "nonviscous" phase (NON-VISCOUS-12), the coefficients were reduced in order to minimize the frictional control of the resolved motions; more specifically, the damping time scales on the $1 / 3^{\circ}$-grid scale is increased by a factor of more than 5. In the additional, 5-yr-long experiment using biharmonic mixing (BIHARM-12), starting again from the spinup of the $1 / 3^{\circ}$ model, the viscosity was chosen to yield an effective damping timescale similar to NON-VISCOUS-12. The parameters chosen for the different experiments are listed in Table 1, in comparison with parameters from precursory studies with highresolution models of the North Atlantic Ocean.

Clearly the $1 / 12$ model experiments are too short for a basin-scale dynamical adjustment on baroclinic time scales, which is commonly believed to be reached after about 10-20 years for a North Atlantic general circulation model. In contrast to the recent studies of Smith et al. (2000) and Paiva et al. (1999), where North Atlantic models of similar resolution were integrated for 10-15 yr, we chose for the present study not to invest all resources into a single high-resolution run, but to obtain some information on parameter dependency through a couple of shorter runs, and to aid the interpretation of the $1 / 12^{\circ}$-cases by a series of more extended experiments with $1 / 3^{\circ}$-resolution.

Figure 1 shows the total kinetic energy (KE) averaged over the Labrador Sea in about 100-m depth, for the whole lengths of VISCOUS-12 and the subsequent experiment NON-VISCOUS-12, together with $3 \mathrm{yr}$ of KE in STANDARD-3 after its spinup phase. It is evident that reducing the viscous damping in NON-VISCOUS12 immediately enhances the KE, by about a factor of 2 in the Labrador Sea. There is, however, a small negative trend in the KE in NON-VISCOUS-12: whether this is due to a longer-term adjustment or to intrinsic interannual variability is not clear. Note, however, the presence of a positive trend of similar magnitude in the $3 \mathrm{yr}$ of the $1 / 3^{\circ}$ model after its 15 -yr-long spinup phase. For the purpose of the present study, that is, the question of the sources of EKE in the Labrador Sea, the short integration period can be considered sufficient since the kinetic energy is quickly adjusted to the refined resolution. Moreover, this quick increase in KE turns out to be almost entirely due to an increase in EKE (as shown below) while the mean KE stays more or less the same in all experiments, a feature resembling previous model studies (e.g., Böning and Budich 1992). 
TABLE 1. A list of the model experiments and parameters, in comparison with other recent high-resolution model studies. Note that all values are referenced to the equator; at higher latitudes the resolution and viscosity/diffusivity are reduced according to $\cos \phi$ (for the biharmonic cases $\cos ^{3} \phi$ ). The diffusive timescale $T_{\text {diff }}$ is calculated from a simple scaling law of, e.g., a tracer equation that yields $T_{\text {diff }}=$ $L^{2} / A_{h}$ for harmonic (harm.) and $T_{\text {diff }}=L^{4} / A_{h}$ for biharmonic (biha.) mixing, and where $L$ denotes the spatial scale chosen as the grid scale of our $13^{\circ}$ model.

\begin{tabular}{|c|c|c|c|c|}
\hline & Grid & Mixing & $T_{\text {diff }}$ (days) & Forcing \\
\hline \multicolumn{5}{|c|}{ Our expts } \\
\hline VISCOUS-12 & $1 / 12^{\circ}$ & Harm. $A_{h}=100 \mathrm{~m}^{2} \mathrm{~s}^{-1}$ & 159 & Monthly \\
\hline NON-VISCOUS-12 & $1 / 12^{\circ}$ & Harm. $A_{h}=20 \mathrm{~m}^{2} \mathrm{~s}^{-1}$ & 794 & Monthly \\
\hline BIHARM-12* & $1 / 12^{\circ}$ & Biha. $A_{h}=2.7 \times 10^{10} \mathrm{~m}^{4} \mathrm{~s}^{-1}$ & 807 & Monthly \\
\hline STANDARD-3 & $1 / 3^{\circ}$ & Biha. $A_{h}=2 \times 10^{11} \mathrm{~m}^{4} \mathrm{~s}^{-1}$ & 109 & Monthly \\
\hline CONSTWIND-3 & $1 / 3^{\circ}$ & Biha. $A_{h}=2 \times 10^{11} \mathrm{~m}^{4} \mathrm{~s}^{-1}$ & 109 & Constant wind \\
\hline CONSTHEATWIND-3 & $1 / 3^{\circ}$ & Biha. $A_{h}^{n}=2 \times 10^{11} \mathrm{~m}^{4} \mathrm{~s}^{-1}$ & 109 & Constant heat flux and wind \\
\hline \multicolumn{5}{|c|}{ Other expts } \\
\hline Beckmann et al. (1994) & $1 / 6^{\circ}$ & Biha. $A_{h}=5 \times 10^{10} \mathrm{~m}^{4} \mathrm{~s}^{-1}$ & 436 & Monthly \\
\hline Smith et al. (2000) & $1 / 10^{\circ}$ & Biha. $A_{h}=2.7 \times 10^{10} \mathrm{~m}^{4} \mathrm{~s}^{;-1}$ & 807 & Daily \\
\hline Paiva et al. (1999) & $1 / 12^{\circ}$ & $\begin{array}{l}\text { Biha. } A_{h}=0.8 \times 10^{10} \mathrm{~m}^{4} \mathrm{~s}^{-1} \\
\quad+\text { Harm. } A_{h}=46 \mathrm{~m}^{2} \mathrm{~s}^{-1}\end{array}$ & $\begin{aligned} 2723 \text { (Biha.) } \\
345 \text { (Harm.) }\end{aligned}$ & Monthly \\
\hline Oschlies (2002) & $1 / 9^{\circ}$ & Biha. $A_{h}=2.8 \times 10^{10} \mathrm{~m}^{4} \mathrm{~s}^{-1}$ & 778 & Monthly \\
\hline
\end{tabular}

* Preliminary experiment; see text for details.

The focus of our diagnostics is on seasonal averaged EKE and energy transfers (averaged over at least $3 \mathrm{yr}$ of the experiments), for winter [January-March (JFM)], spring [April-June (AMJ)], etc. In addition, we will use snapshots of eddy velocity fields and time series for selected sections, to elucidate spatial and temporal characteristics. Note that the energy of the seasonal signal should not be contained in the EKE, since we have made use of seasonal means for the time averages.

\section{Distribution and seasonal cycle of eddy kinetic energy}

Figure 2 shows the annual mean patterns of EKE and mean flow (both averaged over $3 \mathrm{yr}$ ) for a near-surface $(107 \mathrm{~m})$ level of the Labrador Sea in NON-VISCOUS12 (very similar results are obtained in BIHARM-12, not shown). Overall, the area northwest of the subarctic front, away from the eddy-rich branches of the NAC (and its "northwest corner," whose influence in this model case can be seen to penetrate to about $52^{\circ} \mathrm{N}$ ), is

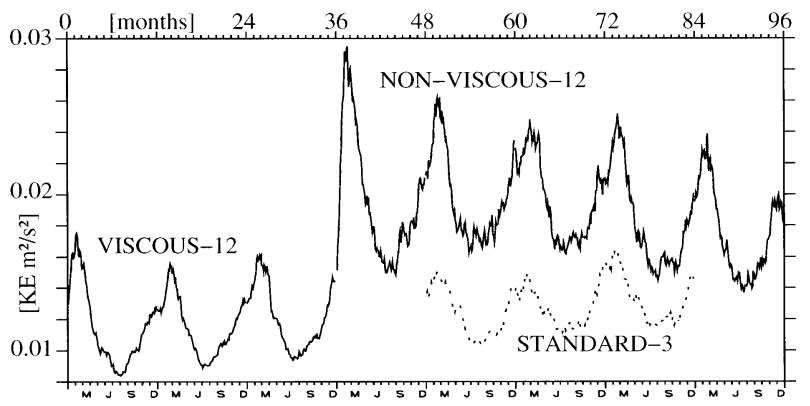

FIG. 1 . The total kinetic energy horizontally averaged $\left(55^{\circ}-65^{\circ} \mathrm{N}\right.$, $60^{\circ}-45^{\circ} \mathrm{W}$ ) in $107-\mathrm{m}$ depth in the Labrador Sea in VISCOUS-12 (solid line, first $3 \mathrm{yr}$ ), NON-VISCOUS-12 (solid line, last $5 \mathrm{yr}$ ), and STANDARD-3 (dotted line). characterized by an only moderate eddy activity. An energy maximum, with values more than $500 \mathrm{~cm}^{2} \mathrm{~s}^{-2}$, extends from the West Greenland continental slope into the interior Labrador Sea near $61^{\circ}-62^{\circ} \mathrm{N}$, obviously associated with the separation from the coastline of parts of the West Greenland Current (WGC). Another area of moderately enhanced EKE, apparently separated both from the eddy fields in the WGC patch and the northwest corner area, shows up along the Labrador Current (LC) over the continental slope of the western Labrador Sea; there the maximum values reach $150 \mathrm{~cm}^{2} \mathrm{~s}^{-2}$. Before proceeding with a description of the seasonality in EKE and its sources we want to compare the model results with some observational estimates of EKE in the Labrador Sea. However, since strength and position of the mean currents are potentially an important factor determining the level of EKE we begin with an assessment of the modeled current strength and structure, facilitated by the expanding database of direct current observations from moorings, drifters and floats released as part of the World Ocean Circulation Experiment (WOCE).

Observational estimates of the total transport of the WGC around Cape Farewell range between 34 and 50 $\mathrm{Sv}\left(\mathrm{Sv} \equiv 10^{6} \mathrm{~m}^{3} \mathrm{~s}^{-1}\right.$; Clarke 1984; Reynauld et al. 1995). In the model (NON-VISCOUS-12), the WGC transports between $37 \mathrm{~Sv}$ at $46^{\circ} \mathrm{W}$ and $47 \mathrm{~Sv}$ downstream of Cape Desolation (compare also Fig. 11 for the mean transport streamfunction). An estimation of cross-stream profiles of near surface currents and currents in 1000-m depth from drifter and hydrographic data in the Labrador Sea is given by Cuny et al. (2002). Figure 3 depicts some of these profiles, for the WGC at Cape Farewell and Cape Desolation and the LC north of the Hamilton Bank, together with the mean currents from NON-VISCOUS-12 (compare also Fig. 10 for the mean WGC structure). At these positions both the LC 


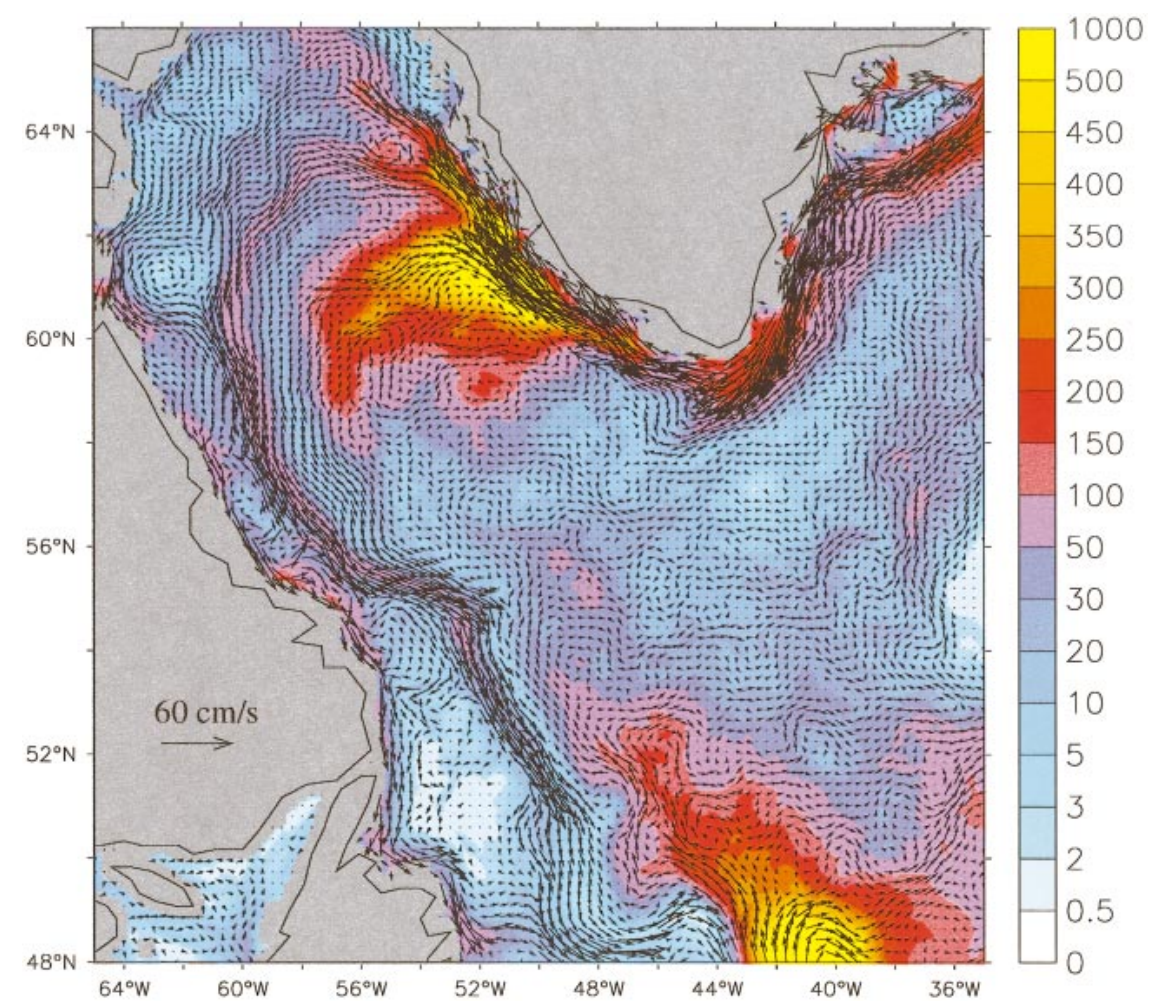

FIG. 2. Eddy kinetic energy $\left(\mathrm{cm}^{2} \mathrm{~s}^{-2}\right)$ in about 100-m depth in the eddy-resolving model (shaded) and the mean near-surface circulation (arrows), both for NON-VISCOUS-12. Note the unequally spaced contour intervals and that the data have been horizontally smoothed $\left(0.2^{\circ}\right.$ Hanning window $)$ prior to plotting.

and the WGC flow along the continental slope between the 1000- and 3000-m isobaths (denoted in the figure). There is a good agreement with the observations, with respect to the position relative to the topography, the profiles, the strengths and the shear of both major boundary currents. The high horizontal resolution and the low frictional damping appear as instrumental in this regard: coarser resolution as in the $13^{\circ}$ model yields lower current strengths and broader profiles (not shown).

Lazier and Wright (1993) describe the LC as composed of a shallow surface-intensified part centered above the 1000-m isobaths, as seen in Fig. 3f) and a "deep" LC with less vertical shear flowing along the 2500-m isobaths. For the core of the deep LC, Fischer and Schott (2002) provide a current profile at 1500-m depth estimated from a combination of mooring and profiling autonomous Lagrangian circulation explorer (PALACE) float data. Figure 4 shows this profile together with two sections of the along-isobath flow in NON-VISCOUS-12 at similar locations, again revealing a good agreement with respect to the position, the profile, and the strength of the deep boundary current. While both model profiles are well within the spread of the individual float observations, the upstream section shows a slightly stronger flow compared to the downstream section. Overall the agreement with respect to the structure and strength of the mean currents suggests that the model provides a useful basis for obtaining insight into eddy generation through instability processes in the Labrador Sea.

The eddy variability patterns simulated in the model can be assessed by comparing with analysis of satellite altimeter data and results from drifter observations. Figure 5 shows the root-mean-square (rms) of sea surface height anomalies (SSHA) diagnosed from NON-VISCOUS-12. The maximum in SSHA rms coincides with the EKE maximum near the separation of the WGC, with values up to $6 \mathrm{~cm}$. A similar amplitude estimated from TOPEX/Poseidon (T/P) altimeter data is given by Prater (2002, his Fig. 3). Values in the more quiet regions-for example, offshore the LC-are less than 2 $\mathrm{cm}$ in the model, somewhat less than the observational minima. This may reflect the noise level due to the observational error of SSHA estimates of about $2-3 \mathrm{~cm}$ (Cheney et al. 1994), or could be due to an impact of high-frequency wind forcing which may contribute to the variance in the more quiet regions of the Labrador Sea (SBD), not accounted for in the present model.

The near-surface kinetic energy maximum in the WGC area (exceeding $500 \mathrm{~cm}^{2} \mathrm{~s}^{-2}$ ) depicted in Fig. 2 resembles the patterns from observational estimates, as derived in a host of altimeter analyses (e.g., White and Heywood 1995; Stammer et al. 2001; Fratantoni 2001; 
WGC at Cape Farewell

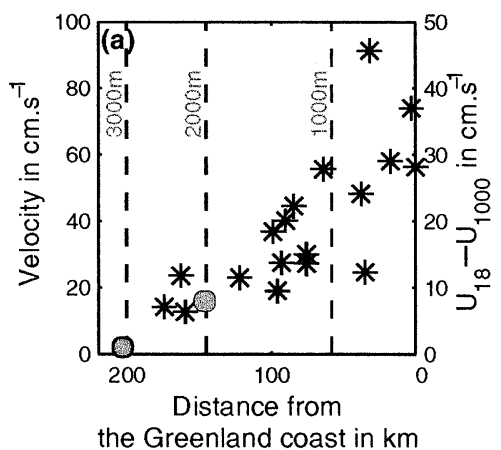

the Greenland coast in $\mathrm{km}$

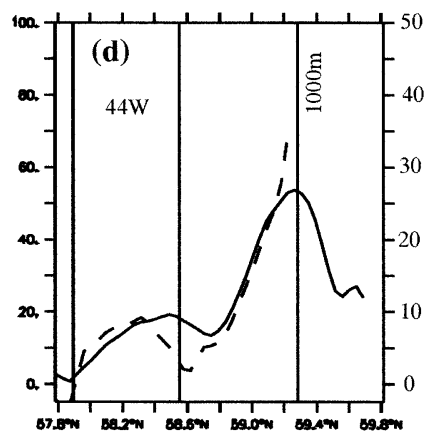

WGC at Cape Desolation

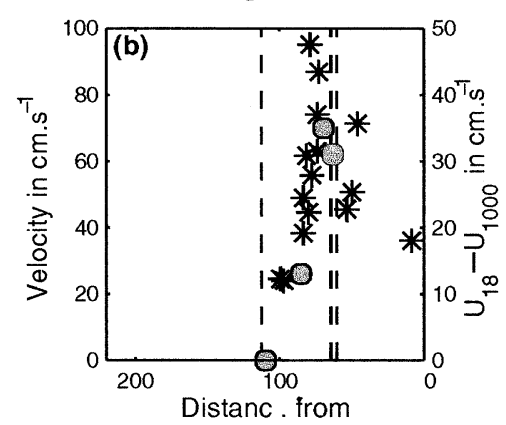

the Greenland coast in $\mathrm{km}$

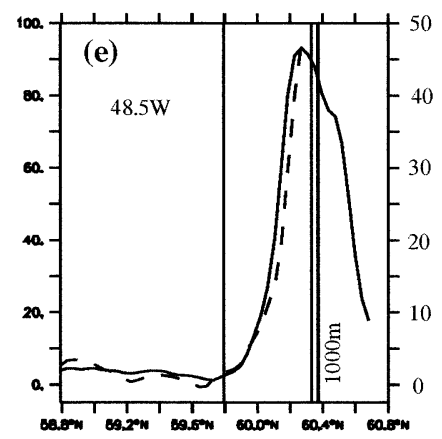

LC north of Hamilton Bank
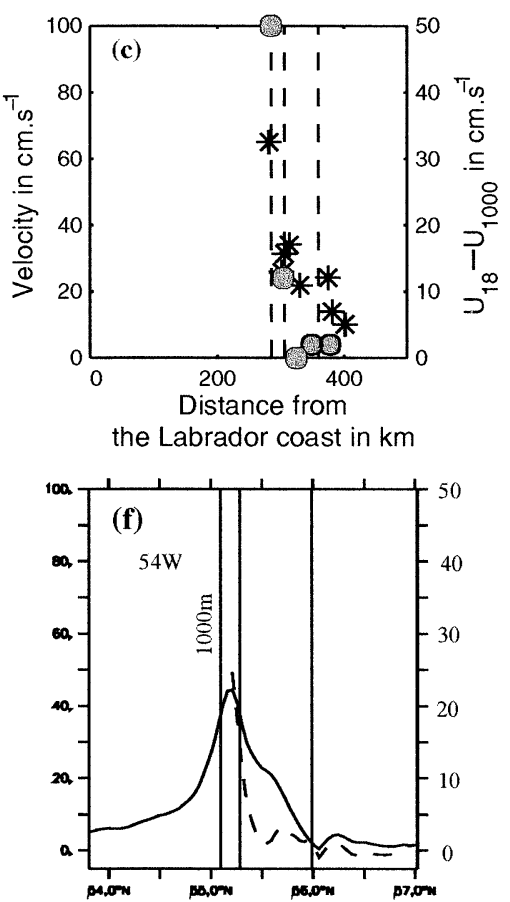

FIG. 3. (a)-(c) Current profiles of the West Greenland Current (WGC) and the Labrador Current (LC) estimated from surface drifter data and hydrographic sections reproduced from Cuny et al. (2002) (their Figs. 8a,b,f). Stars give the speed ( $\mathrm{cm} \mathrm{s}^{-1}$ ) of the surface drifters as they crossed each section, denoted in the figure. The filled circles give the speed difference between 18 and $1000 \mathrm{~m}$ deduced from the hydrographic sections. The locations of the 1000-, 2000-, and 3000-m isobaths are indicated. Note the different vertical axis (on the right) for the shear in the figure. (d)-(f) Current profiles (3-yr averages) in NON-VISCOUS-12 at similar locations. Solid lines denote the speed in 15-m depth, dashed lines the difference in speed between 15- and 1000-m depth. The locations of the 1000-, 2000-, and 3000-m isobaths of the model topography are indicated. Note again the different vertical axis (on the right) for the shear in the figure.

BMS). However, quantitative comparisons of EKE need to be viewed with some caution: For example, altimetric values obtained from analysis of the cross-track velocity components along individual altimeter tracks, to some degree depend on methodogical details, such as alongtrack smoothing or manual elimination of unusual values, applied to filter out small-scale noise. This is reflected in the spread of the reported maxima for the WGC patch in EKE, ranging from 300 (Fratantoni 2001) to 200-500 $\mathrm{cm}^{2} \mathrm{~s}^{-2}$ (White and Heywood 1995; Stammer et al. 2001). BMS (their Fig. 2a) give $400 \mathrm{~cm}^{2} \mathrm{~s}^{-2}$ for the WGC maximum and depict more small-scale structures, apparently due to application of less spatial smoothing.

Estimates of EKE derived from surface drifter data have recently become available with sufficient coverage (for at least parts of the Labrador Sea). While the EKE patterns for the Atlantic and the Labrador Sea are similar to altimetric estimates, in general the drifter-derived estimates tend to be higher than the altimetric-derived estimates. Fratantoni (2001) notes drifter-derived EKE values being $O\left(100 \mathrm{~cm}^{2} \mathrm{~s}^{-2}\right)$ higher than altimeter-derived values for most parts of the Atlantic. For the WGC patch in the Labrador Sea, estimated from surface drifter data, Cuny et al. (2002) show maximum values ex- ceeding $400 \mathrm{~cm}^{2} \mathrm{~s}^{-2}$ and Fratantoni (2001) reports a maximum of $450 \mathrm{~cm}^{2} \mathrm{~s}^{-2}$.

A similar distribution of EKE over the northern Labrador Sea was also exhibited by the $1 / 1^{\circ}$ model of Smith et al. (2000) $)^{3}$ where an EKE patch more than $500 \mathrm{~cm}^{2}$ $\mathrm{s}^{-2}$ was obtained in the WGC area. We note here also that with respect to both the geographical patterns and the values of EKE in the Labrador Sea, our (preliminary) model case with biharmonic friction (BIHARM-12) closely resembles the results of the main case using harmonic friction. Hence, taken together, the different high-resolution model solutions indicate a certain robustness of the simulated WGC patch with respect to the choices of friction schemes and coefficients. This does not hold to the same degree for the EKE in the southwestern Labrador Sea, in which a distinct minimum along the LC shows up in the experiment by Smith

\footnotetext{
${ }^{3}$ In the experiment of Smith et al. (2000), the scaling law for viscosity/diffusivity was in error, leading to too-low viscosities/diffusivities in the northern North Atlantic in their model by a factor of $\cos ^{3} \phi$ (R. Smith 2001, personal communication). We are referring here to a repeated experiment with correct scaling which, for example, shows much reduced penetration of the northwest corner into the Labrador Sea (R. Smith 2001, personal communication).
} 


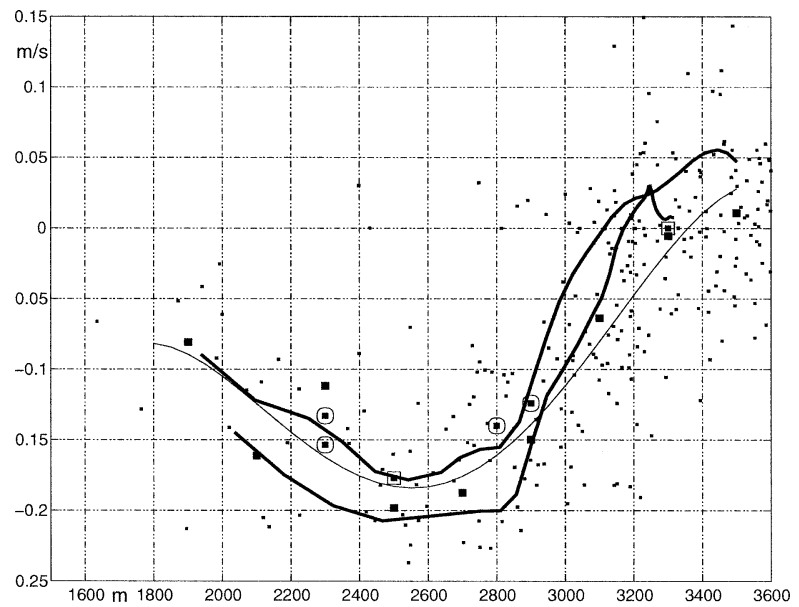

FIG. 4. Cross-stream profile of the deep Labrador Current estimated from float and mooring data, reproduced from Fischer and Schott (2002), their Fig. 2. Shown is the component tangential to the slope (negative values are roughly southeastward) in 1500-m depth in the latitude range $51^{\circ}-56^{\circ} \mathrm{N}$ from individual float (small dots) and mooring (big dots) observations (the thin black line is a fit to the observations). The thick black lines denote two current profiles at the same depth of the deep Labrador Current in NON-VISCOUS-12 (3-yr averages) at $54^{\circ} \mathrm{N}$ and at $54^{\circ} \mathrm{W}$. Shown is the (negative) zonal velocity for the former section in which the flow is roughly eastward and the meridional velocity for the latter section in which the flow is roughly southward. Both profiles are plotted versus topography (undiscretized) at each section. et al. (2000), in contrast to experiments NON-VISCOUS-12 as well as BIHARM-12. We will discuss this point further in section 5 .

\section{a. Seasonal cycle of eddy kinetic energy}

The eddy intensity in the Labrador Sea is characterized by a pronounced seasonal cycle. Seasonal anomalies (3-yr mean of deviations from the mean annual cycle) of the near surface EKE are shown in Fig. 6. For both the WGC and the LC eddy fields the EKE reaches a maximum during the winter season (JFM), and minimum levels of EKE are found during summer [JulyAugust-September (JAS)] and autumn [October-November-December (OND)]. The annual range locally exceeds $200-300 \mathrm{~cm}^{2} \mathrm{~s}^{-2}$ near the separation of the WGC and reaches about $100 \mathrm{~cm}^{2} \mathrm{~s}^{-2}$ along the LC.

Both the annual mean and the annual amplitude of the simulated EKE over the northern Labrador Sea are sensitive to the choice of the friction parameters in the model. Figure 7 gives a quantitative comparison of various model cases with the observational estimates of White and Heywood (1995), by depicting the temporal variation of EKE averaged over the same area of the basin. For the two $1 / 12^{\circ}$ model cases, the time series shown cover the simulated period after the first year of integration; the $1 / 3^{\circ}$ curve represents a period several

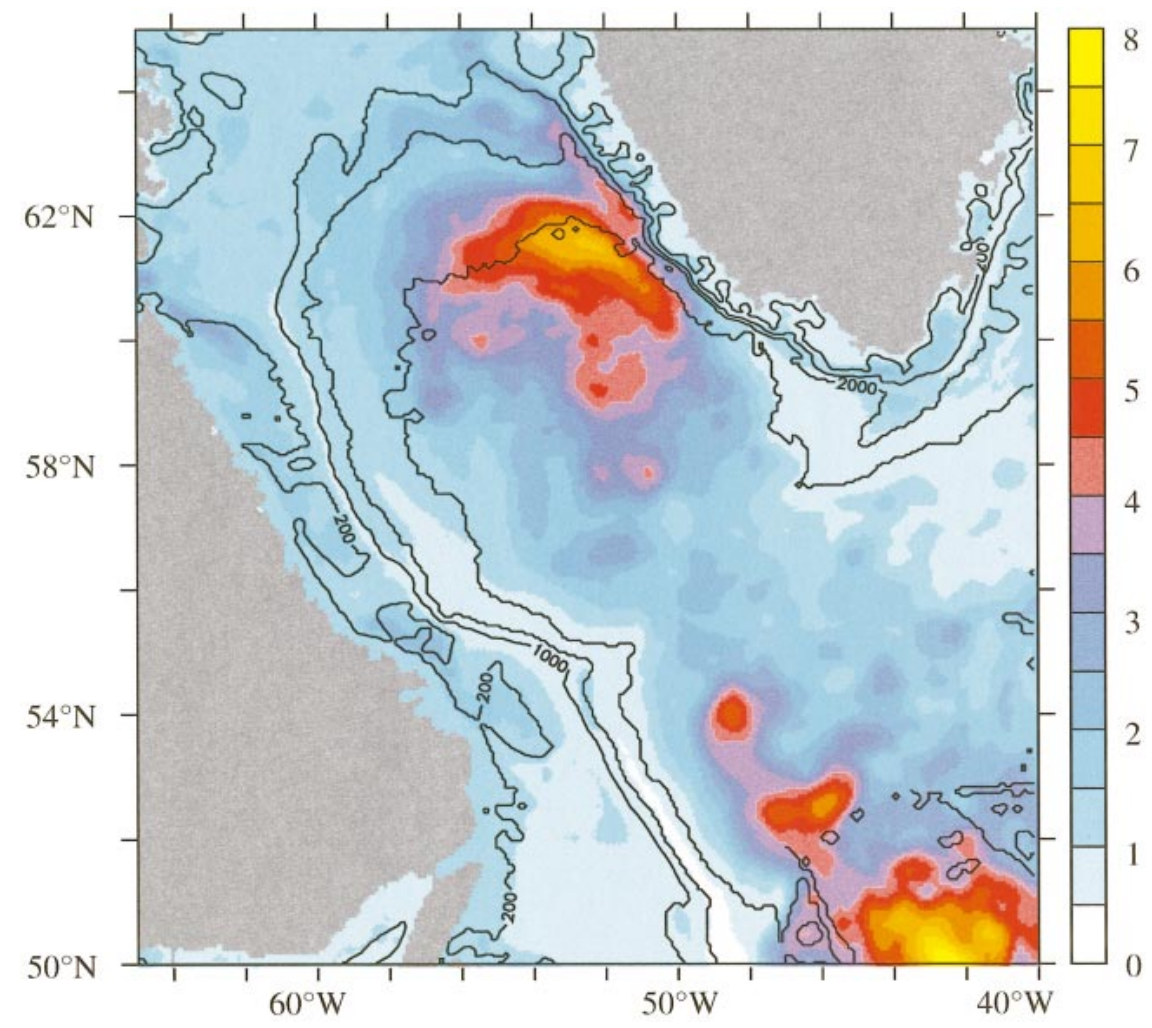

FIG. 5. Root-mean-square of the diagnosed sea surface height anomalies $(3 \mathrm{yr})$ in experiment NON-VISCOUS-12 (cm). Contour interval is $0.5 \mathrm{~cm}$. Overlayed are the 200-, 1000-, 2000-, 3000-, and $4000-\mathrm{m}$ isobaths of the model topography. 


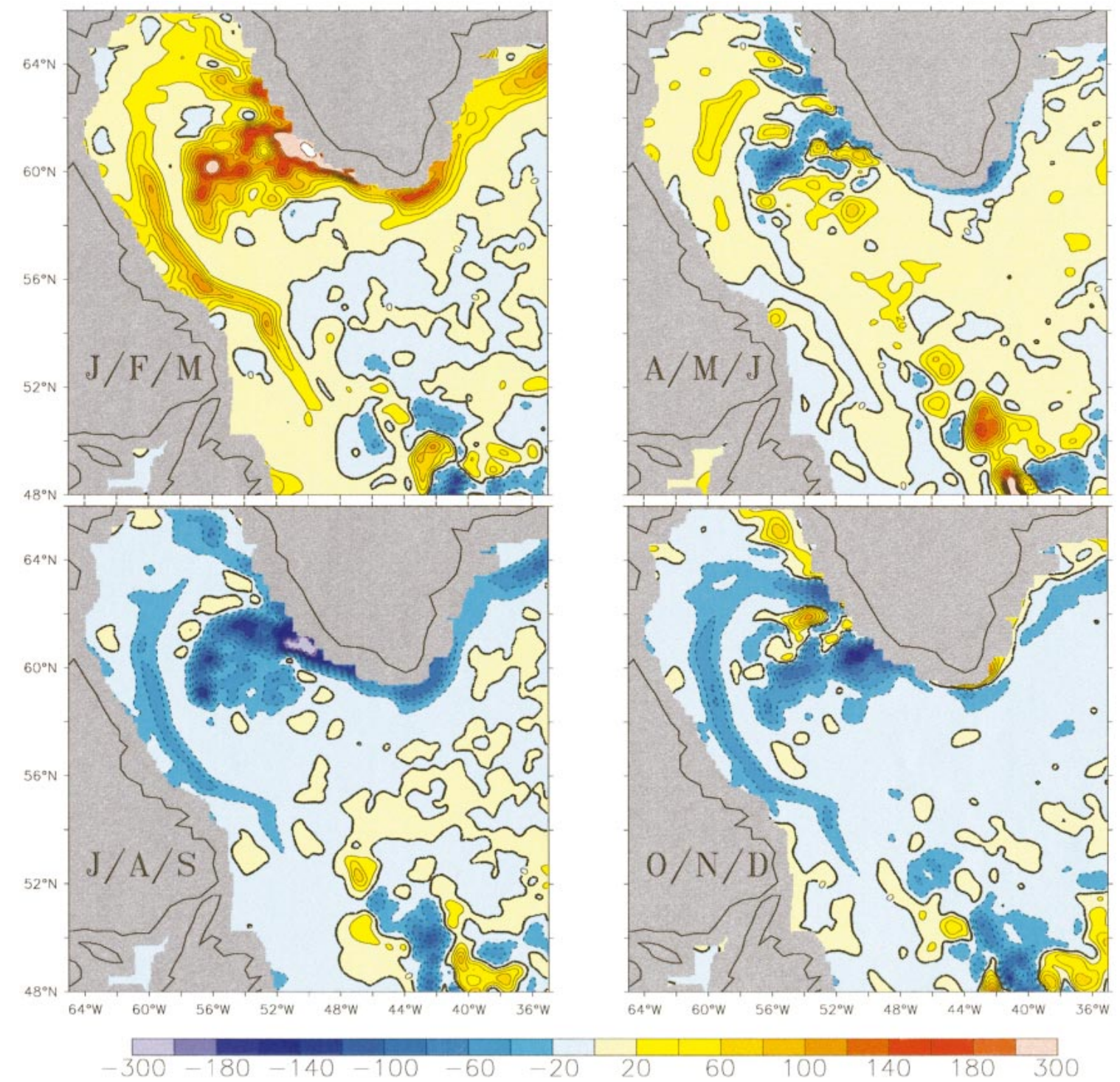

FIG. 6. Seasonal anomalies of the EKE $\left(\mathrm{cm}^{2} \mathrm{~s}^{-2}\right)$ in $107-\mathrm{m}$ depth in the Labrador Sea. Note the unequally spaced tails of the contour interval and that the data have been horizontally smoothed $\left(0.6^{\circ}\right.$ Hanning window) prior to plotting.

years after the spinup (results from BIHARM-12 are not shown here: its EKE values are similar as in NONVISCOUS-12).

The observed amplitude is well reproduced in the main $1 / 12{ }^{\circ}$ model case (NON-VISCOUS-12). The observed and simulated phases of the seasonal signal appear to deviate which, however, may partly be a result of somewhat differing methodologies: in the model time series of seasonal EKE values, the maxima always occur during the months of JFM, followed by AMJ, while the harmonic analysis of the altimetric time series indicated a maximum in early March (White and Heywood 1995). There is also a close agreement between NON-VISCOUS-12 and time series of area-averaged, altimeterderived estimates of EKE given by BMS with respect to both the amplitude as well as the phase of the seasonal cycle in this area.

The higher mixing coefficients chosen in VISCOUS12 yield a much reduced energy level, of similar order of magnitude as in the $13^{\circ}$ case shown for comparison. It is interesting to note that the coarser model qualitatively, yet not quantitatively, reproduces the behavior of the finer model: there is a seasonal cycle with a maximum during winter, as seen in Fig. 14, and, not shown, a similar spatial pattern with an enhanced EKE patch in the WGC area. Note also that the mean kinetic energy (MKE) stays almost the same in all experiments (Fig. 1).

Overall, the features of the EKE as simulated in the "nonviscous" $1 / 12{ }^{\circ}$ model version appear fairly repre- 


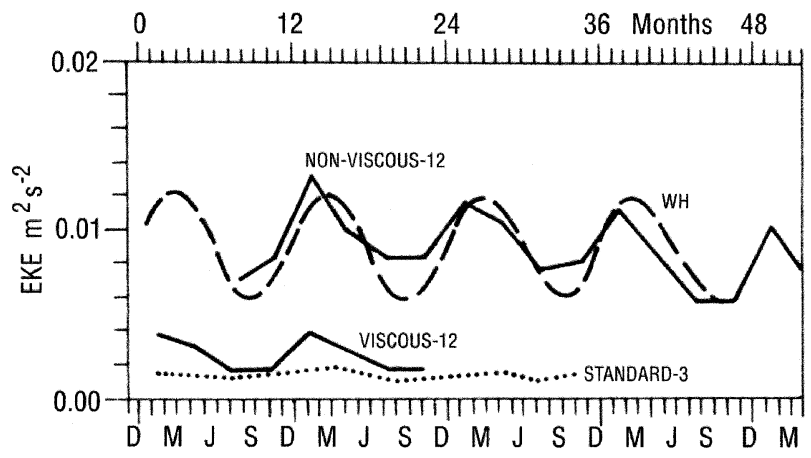

FIG. 7. Observed and simulated temporal variability of the horizontally averaged $\left(55^{\circ}-65^{\circ} \mathrm{N}, 60^{\circ}-45^{\circ} \mathrm{W}\right)$ near-surface EKE $\left(\mathrm{cm}^{2} \mathrm{~s}^{-2}\right)$ in the Labrador Sea. Time series of quarterly means from the last 2 yr of VISCOUS-12 and the last $4 \mathrm{yr}$ of NON-VISCOUS-12 are compared with the annual harmonic of the EKE estimated from altimetric observations (reproduced from White and Heywood 1995, their Fig. $7 \mathrm{~g}$, denoted $\mathrm{WH}$ ). Also shown is the corresponding time series of STANDARD-3.

sentative of the observed fields: with respect to its spatial pattern (with a maximum in the WGC area), to the amplitudes of the annual mean and the annual cycle, and to the phase of the annual march. Since the model was forced with monthly mean atmospheric fluxes only, this EKE can only be generated by internal instability mechanisms. Before proceeding with an analysis of the origin of the seasonally varying EKE maxima by inspecting the energy transfer rates in the EKE budget in section 4 , we will briefly turn in the next section to a description of the features of the eddies spawned by the WGC.

\section{b. Structure of eddies in the Labrador Sea}

Figure 8 shows a representative sequence of near surface snapshots of velocity and relative vorticity starting in mid January in steps of 12 days to provide the reader with a glimpse of the instantaneous eddy field in the Labrador Sea. A train of mesoscale eddies is shed from the WGC at its separation point off Greenland's west coast, coinciding with the maximum of the EKE in the Labrador Sea, and drifts into the interior Labrador Sea. Almost all of these eddies are anticyclonic, carrying warm and saline water into the interior. Animations of similar sequences (which are available online at http://www.ifm.uni-kiel.de/fb/fb1/tm/research/ FLAME/Publications/EB2001_animations.html) give the impression that eddies drifting to the west toward the vicinity of the LC are rapidly advected to the south, while eddies which drift southeastward into the interior Labrador Sea can reside there up to about half a year until their buoyancy signature is damped out by surface heat fluxes and dissipation.

Figure 9 shows a section of potential density and zonal velocity through a similar snapshot to depict a typical vertical structure of the eddy field in the central Labrador Sea. Here, two anticyclonic and one cyclonic eddies show up. Note that this is one of the few examples of a strong cyclonic eddy in the central Labrador Sea we are able to find in the model solution. While the anticyclones show a surface intensified zonal flow, with a speed up to $45 \mathrm{~cm} \mathrm{~s}^{-1}$ at the surface and only a couple of centimeters per second below about $1000 \mathrm{~m}$, the cyclonic eddy has a more depth-independent structure with maximum speeds of about $25 \mathrm{~cm} \mathrm{~s}^{-1}$ down to the bottom. The animations suggest that both the dominating anticyclones and the fewer and, generally, weaker cyclones originate from the WGC separation. Since upstream of Cape Desolation, cyclonic relative vorticity can be found at the offshore flank of the WGC, while anticyclonic vorticity resides in the shallower, onshore flank it is tempting to relate the origin of the cyclonic eddies with the more barotropic flow offshore and the anticyclones with the more baroclinic and shallower onshore flank of the WGC.

Along the shelf of Labrador, the sequence in Fig. 8 reveals a nearly simultaneous occurrence of enhanced, small-scale fluctuations in the LC. These fluctuations are present every year in the model (in all $11_{12}^{\circ}$ experiments) around the end of January. Note that the spatial scale of these fluctuations is much larger than the grid scale. Their origin will be examined in section 4, also on the basis of the energy transfer rates.

\section{Sources of eddy kinetic energy}

\section{a. West Greenland Current}

The prominent patch of enhanced EKE in the WGC points to a change in the stability characteristics of the current upon its turning around the tip of Greenland. Vertical cross sections of the East/West Greenland Current in that area are shown in Fig. 10. Upstream of Cape Farewell, the mean current is centered on the continental slope roughly above 1000-2000-m depth, with nearsurface speeds of about 50-60 $\mathrm{cm} \mathrm{s}^{-1}$. Downstream of the Cape, near $48^{\circ} \mathrm{W}$, the continental slope considerably steepen, forcing the current into deeper water: the meridional section at $48^{\circ} \mathrm{W}$ exhibits a much deeper (3000 m) and narrower current profile, with surface speeds up to about $90 \mathrm{~cm} \mathrm{~s}^{-1}$.

A close-up view of the horizontal patterns in the area also illustrates the apparent relation between topographic features, mean flow contours, and eddy energy (Fig. 11). East and south of Cape Farewell the mean flow smoothly follows the 1000-2000-m isobaths and is associated with very weak EKE. The topographic guidance is partly interrupted near $48^{\circ} \mathrm{W}$ where the current has to cross the $3000-\mathrm{m}$ isobath before reattaching to the continental slope. Downstream of $48^{\circ} \mathrm{W}$ the flow exhibits the pronounced maximum of EKE in the Labrador Sea, coinciding with the separation of parts of the WGC into the interior Labrador Sea (compare also the near surface mean circulation in Fig. 2)

In order to more closely identify the area in which 


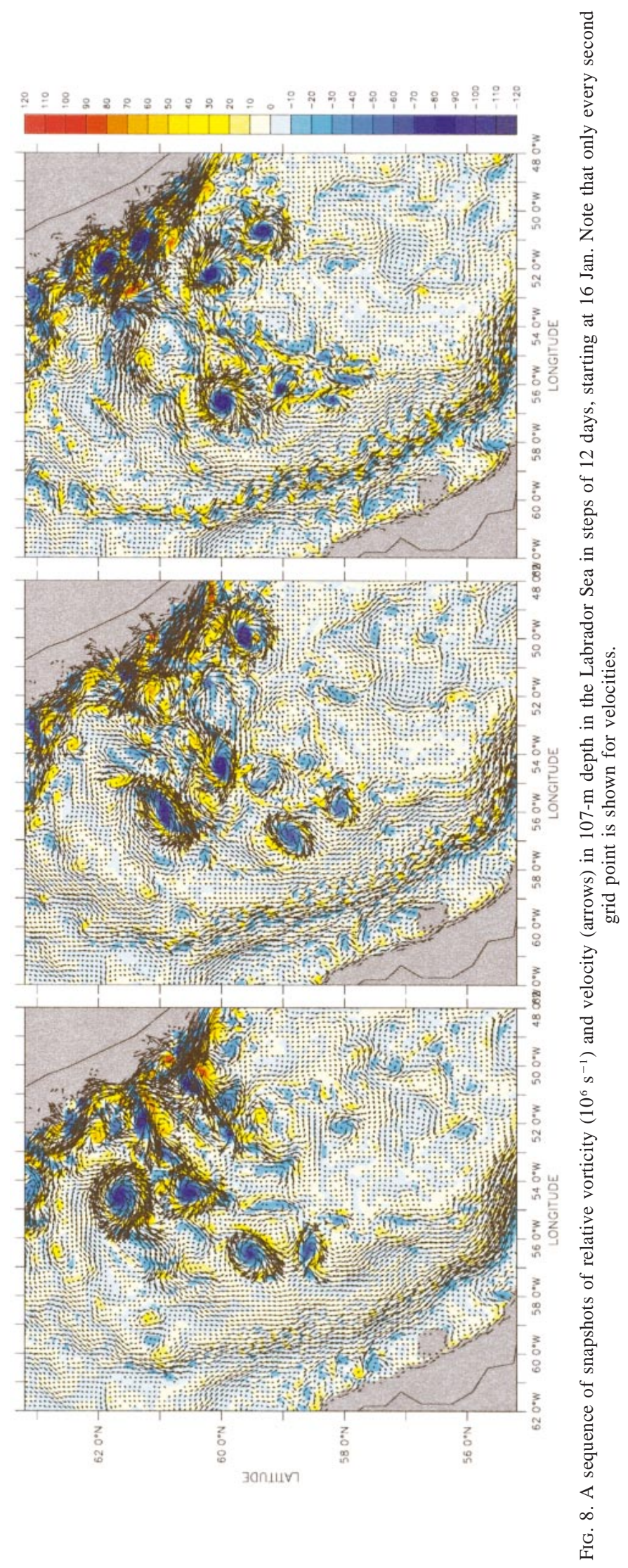




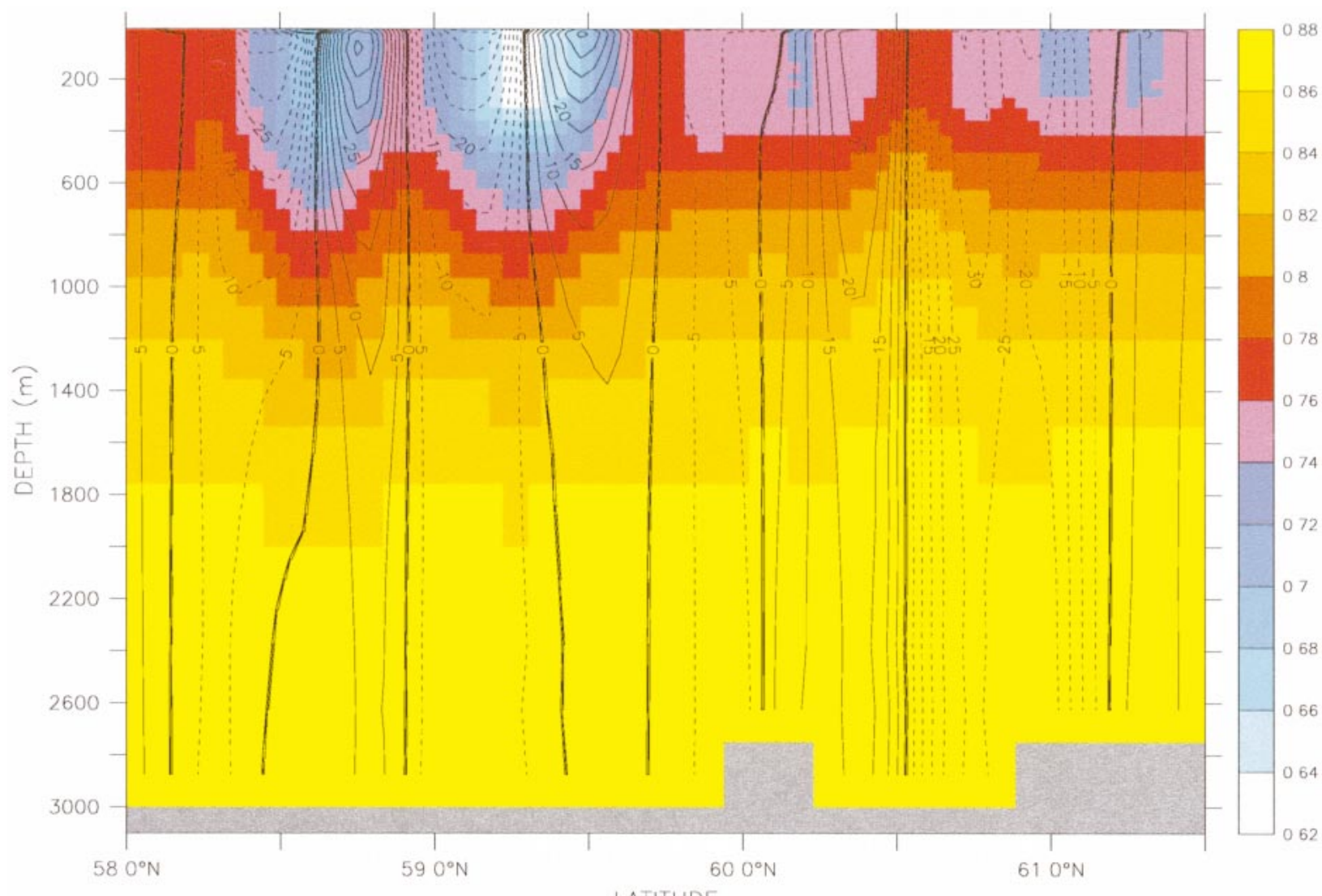

FIG. 9. Vertical section of potential density (density referenced to 0 dbar minus $1027.0 \mathrm{~kg} \mathrm{~m}^{-3}$ ) and zonal velocity (contoured) along $56.9^{\circ} \mathrm{W}$ with two anticyclonic eddies and a cyclonic one.

the current becomes unstable, and to elucidate the cause of the seasonality in the eddy field downstream of Cape Farewell, we turn to an inspection of the energy being transferred from the mean flow into the eddy field. A useful way of examining the energetics of a turbulent flow in a closed domain is to calculate its energy budget in the form introduced by Lorenz (1955), showing the external sources and sinks, and the energy conversions between the various components of the total (mechanical) energy. However, the situation becomes consid-

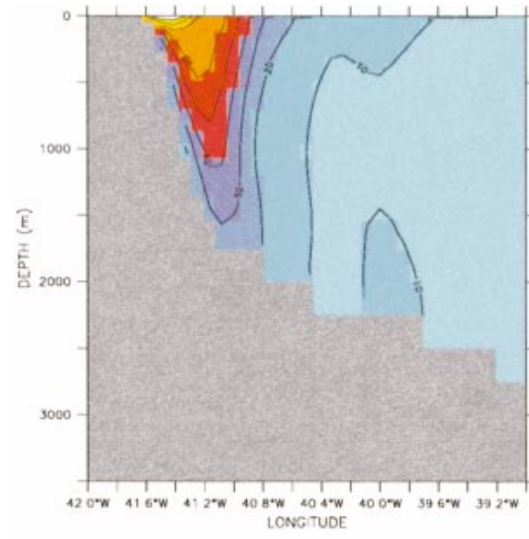

a)

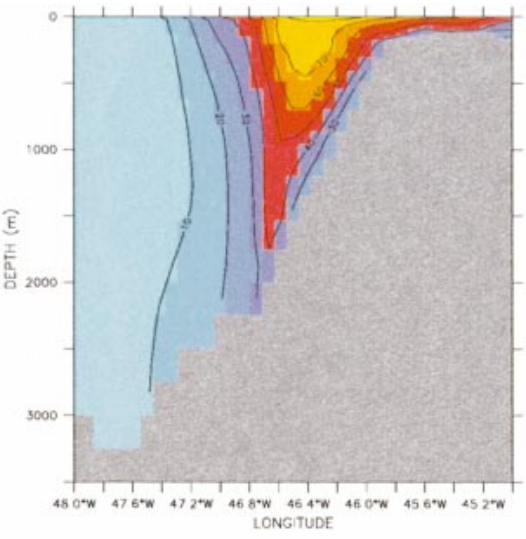

b)

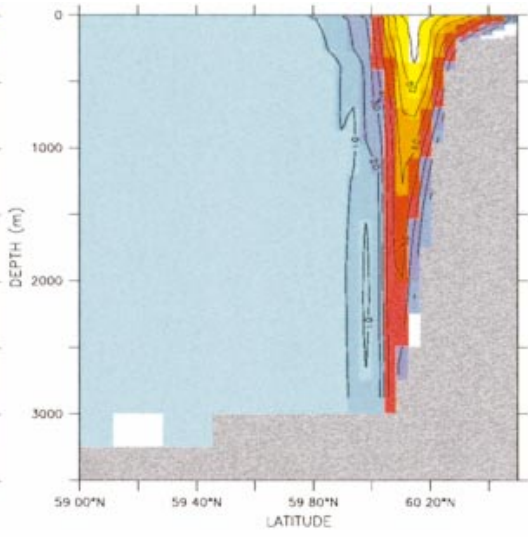

c)

FIG. 10. Cross sections of the mean flow speed around the southern tip of Greenland, illustrating the change in topographic slopes and associated deepening of the WGC downstream of Cape Farewell (CF). Isotachs $\left(\mathrm{cm} \mathrm{s}^{-1}\right)$ depict the speed of the southward flow upstream of $\mathrm{CF}$ at $61^{\circ} \mathrm{N}$ (a), of the northward flow downstream of the southern tip of CF along $59.5^{\circ} \mathrm{N}$ (b), and of the westward flow at $48^{\circ} \mathrm{W}$ (c). 


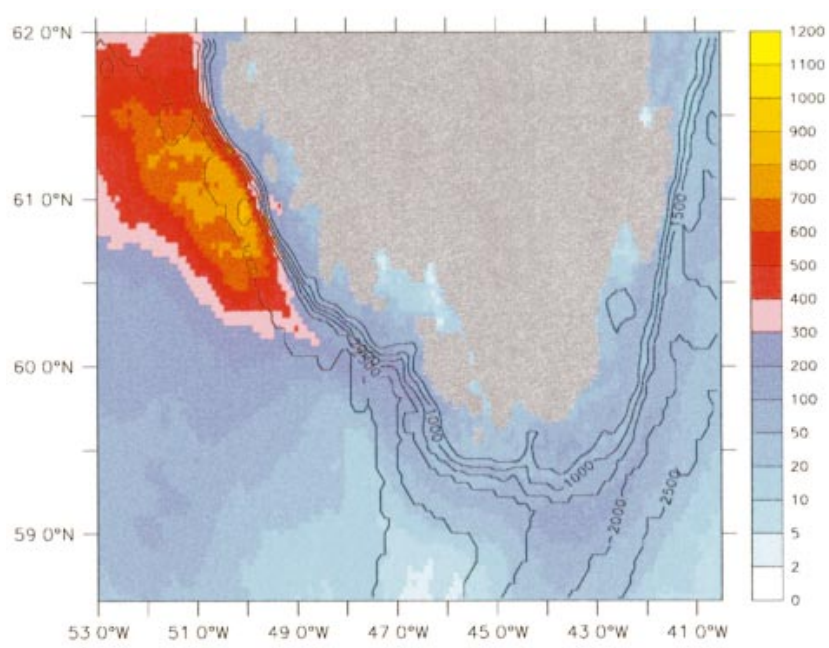

c)

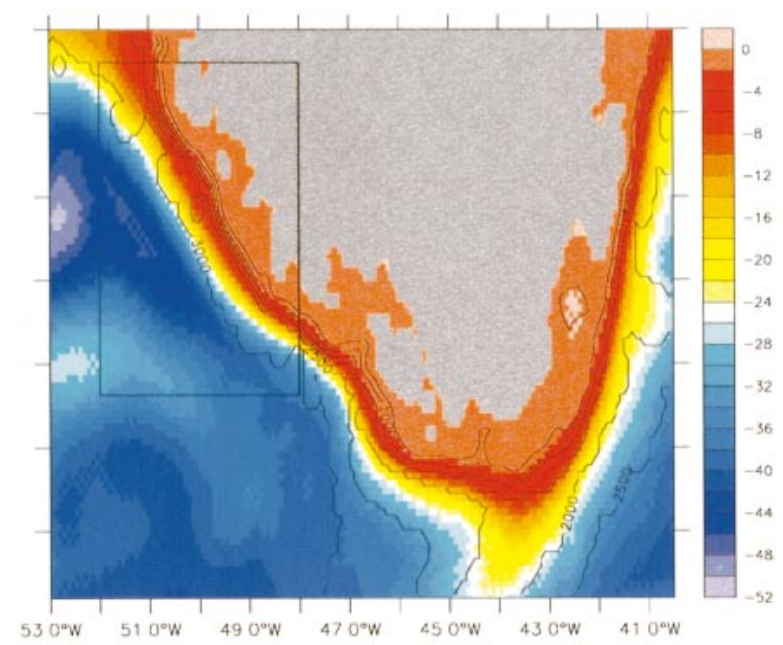

b)

FIG. 11. (a) Eddy kinetic energy, vertically averaged between 100- and 400-m depth $\left(\mathrm{cm}^{2} \mathrm{~s}^{-2}\right)$, and (b) streamfunction of the mean flow $(\mathrm{Sv})$ in relation to the isobaths (1500-m contour interval) of the continental slope in the vicinity of Cape Farewell. The indicated subregion in the WGC is zoomed up in Fig. 12 for illustrating the energy transfers.

erably more complex when considering open subregions of fluid: There, transports of energy due to mean and eddy advections and due to divergence of mean and eddy pressure work are involved as well (e.g., Harrison and Robinson 1978; Treguier 1992). While a complete calculation of the mean and eddy energy budget is beyond the scope of the present study, a first indication of the nature of the instability mechanism can be obtained by considering the energy transfer rates into the energy of the eddies from either the potential energy or the kinetic energy of the mean flow.

The former, corresponding to baroclinic instability, is given by ${ }^{4}$

$$
T_{2}=g \int d V\left(\frac{\partial \overline{\sigma_{\Theta}}}{\partial z}\right)^{-1}\left(\overline{u^{\prime} \rho^{\prime}} \frac{\partial \bar{\rho}}{\partial x}+\overline{v^{\prime} \rho^{\prime}} \frac{\partial \bar{\rho}}{\partial y}\right)
$$

and the latter, representing the energy transfer ${ }^{5}$ due to the work of the Reynolds stresses against the mean shear (which, if positive, represents barotropic instability) is given by

$$
T_{4}=\rho_{0}^{-1} \int d V \overline{u^{\prime} u^{\prime}} \frac{\partial \bar{u}}{\partial x}+\overline{u^{\prime} v^{\prime}}\left(\frac{\partial \bar{u}}{\partial x}+\frac{\partial \bar{v}}{\partial y}\right)+\overline{v^{\prime} v^{\prime}} \frac{\partial \bar{v}}{\partial y},
$$

where overbars denote (seasonal) time averages, the primes deviations from these means, $u$ and $v$ the zonal and meridional velocities, $\rho$ the in situ (model) density, $\sigma_{\Theta}$ a horizontally averaged potential density referenced

\footnotetext{
${ }^{4}$ The notation follows Beckmann et al. (1994).

${ }^{5}$ Note that for an open region the energy transfer due to Reynolds interaction work does not represent a conversion term. The $T_{4}$ as defined gives the change of EKE due to this interaction, it differs from the change of the mean kinetic energy due to the interaction.
}

to the surface, and $\rho_{0}$ a reference (in situ) density. Because the horizontal patterns of the transfer terms are, as typical also of previous model studies, dominated by small-scale structures, we show $T_{2}$ and $T_{4}$ vertically averaged $(100-400 \mathrm{~m})$ and horizontally smoothed $\left(1 / 2^{\circ} \mathrm{Han}-\right.$ ning window). Note also that the total EKE budget of a small open subregion of fluid can actually be dominated by advection of EKE; hence the two transfer rates can only be taken as a qualitative description of the relative importance of the two instability mechanisms.

Figure 12 shows $T_{2}$ and $T_{4}$, respectively, for the region denoted in Fig. 11a. The situation in the WGC apparently differs from open ocean regions where $T_{4}$ is usually of minor importance for the production of EKE (e.g., Beckmann et al. 1994). The unique situation is attributable to the high horizontal shear of the WGC in the area of the steep continental slope just downstream of Cape Desolation which locally tends to favor a dominance of barotropic instability $\left(T_{4}\right)$ for the production of EKE: Fig. 12 reveals a maximum of $T_{4}$ in the center of the region of growing instabilities near Cape Desolation. Only near the coastline baroclinic instability $\left(T_{2}\right)$ contributes in a similar order of magnitude.

The dominance of $T_{4}$ is also manifested in the seasonality of the EKE patch, which can be attributed almost exclusively to the seasonality in $T_{4}$, whereas $T_{2}$ shows no pronounced seasonal cycle (not shown). Figure 13a shows seasonal averages of $T_{4}$ for a meridional section along $48^{\circ} \mathrm{W}$. A maximum for the winter season (JFM) is obvious. The seasonal cycle in the energy transfer closely follows the variations in the mean flow, as indicated, for example, by the zonal velocity at $100 \mathrm{~m}$ averaged over the core of the WGC (Fig. 13b). The seasonal variation of the WGC, with maximum speed in December, hence 

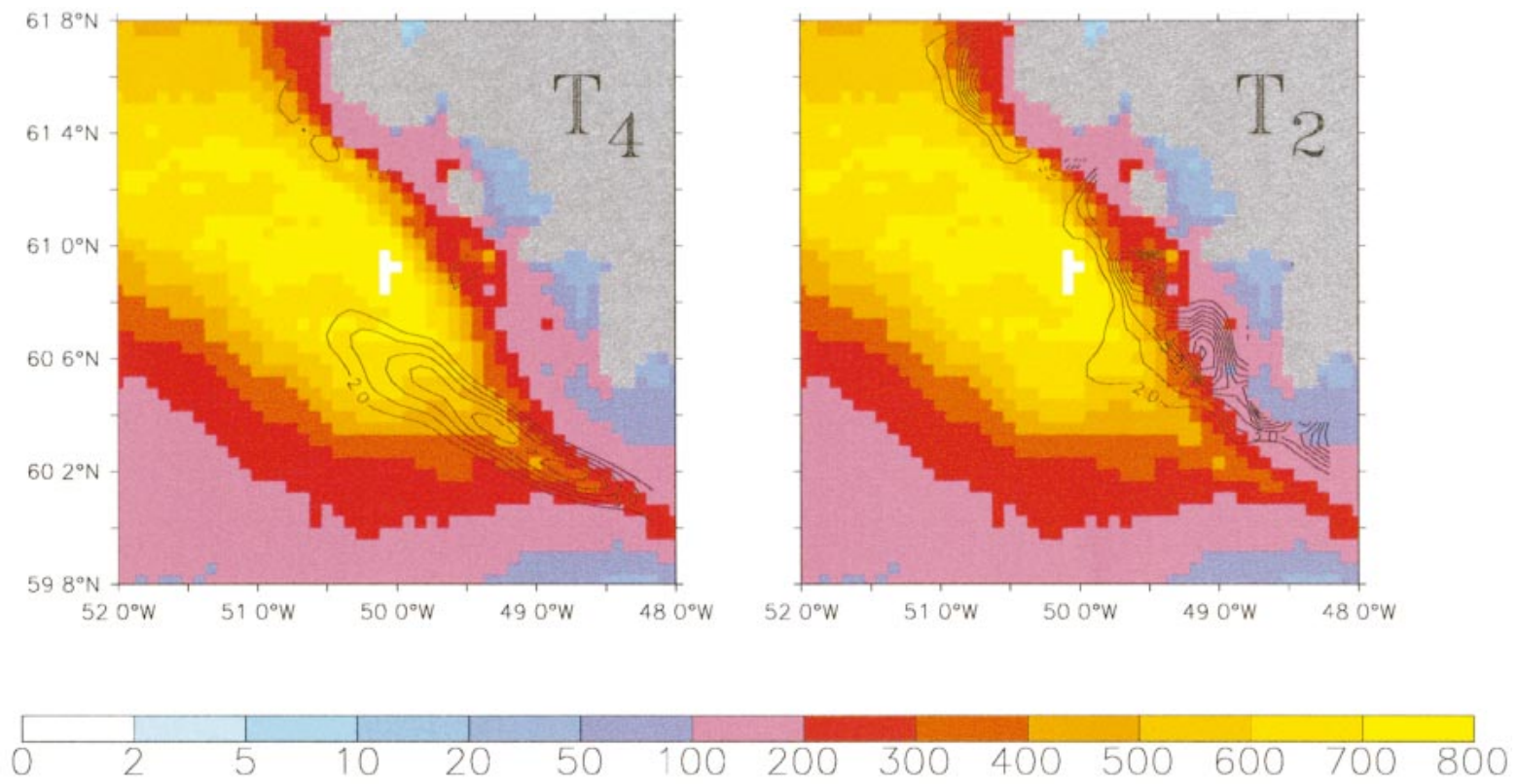

FIG. 12. Eddy kinetic energy (shaded; $\mathrm{cm}^{2} \mathrm{~s}^{-2}$ ) and energy transfer terms (contoured) in the WGC (all vertically averaged from 100- to 400-m depth). (a) Transfer from mean kinetic energy to eddy kinetic energy $\left(T_{4}\right)$, associated with barotropic instability of the mean flow. (b) Transfer from mean potential energy to eddy potential energy $\left(T_{2}\right)$, associated with baroclinic instability of the mean flow. Contour interval is the same for both terms, $2 \times 10^{-10} \mathrm{~m}^{2} \mathrm{~s}^{-3}$.

appears as a main factor responsible for the seasonality in the EKE maximum further downstream.

The companion experiments with the $1 / 3^{\circ}$ model version offer the possibility to further elucidate the relation between the strength of the WGC and the EKE in that region. Figure 14 shows the near surface EKE averaged over the Labrador Sea together with the strength of the WGC for three different experiments. The seasonal cycle of EKE in the $13^{\circ}$ model "standard case" (STANDARD-3), with a maximum in winter, is qualitatively similar to the $1 / 12{ }^{\circ}$ model results. This similarity also holds for the spatial pattern of the annual mean EKE (not shown) and the seasonal cycle of the enhanced EKE patch; however, the amplitudes are much smaller, even compared to VISCOUS-12. Removal of the seasonal cycle in the wind stress (CONSTWIND-3) leads to a shift in the maximum strength of the WGC as well as in the maximum EKE to spring (AMJ), however, without significantly affecting the amplitude of EKE; the slight increase in the mean transport corresponds to a somewhat higher annual mean energy level. In contrast, the seasonal cycle in both the WGC transport and the EKE fades away upon removal of the seasonal cycle in the surface heat flux (CONSTHEATWIND-3). In this model case, after five years of integration, there is still a trend in both measures, apparently reflecting the continuing, slow change in the hydrographic properties of the deep water masses due to the disappearance of deep winter convection in this case, and its effect on the boundary currents due to the associated changes in the bottom pressure torque (Gerdes and Köberle 1995).
Overall, the results depicted in Fig. 14 clearly suggest a relation between the intensity of the WGC and the level of EKE in the area.

Figure 14 shows that the WGC in the instability area near Cape Desolation is influenced by both the seasonality in heat flux and wind stress. However, a broader perspective of the role of the wind forcing in the seasonal cycle of the mean flow, especially the boundary currents including the WGC is provided by Fig. 15, showing the variance of the annual cycle of the barotropic streamfunction in CONSTWIND-3 as compared with the standard case including the seasonal cycle in the wind forcing. It is obvious that in most parts of the Labrador Sea the seasonality in the volume transport is primarily related to the wind stress forcing. This is in agreement with previous results-for example, Greatbatch and Goulding (1989) obtained in a linear barotropic model solely driven by realistic wind stress forcing a seasonal cycle in the transport of the LC comparable to observational estimates (Lazier and Wright 1993). However, in our model the seasonality of the mean flow can be associated in a few region as well with the seasonal cycle in the buoyancy fluxes. ${ }^{6}$ Figure 15 suggests as one of these regions the WGC instability area near Cape Desolation which, in turn appears to be essential in influencing the level of the EKE in the Labrador Sea.

\footnotetext{
${ }^{6}$ Note that in comparison with the other factors, seasonality in the freshwater flux, in the way it is implemented in the present modelthat is, by relaxation of the surface salinity to a seasonal climatology-appears of minor influence.
} 

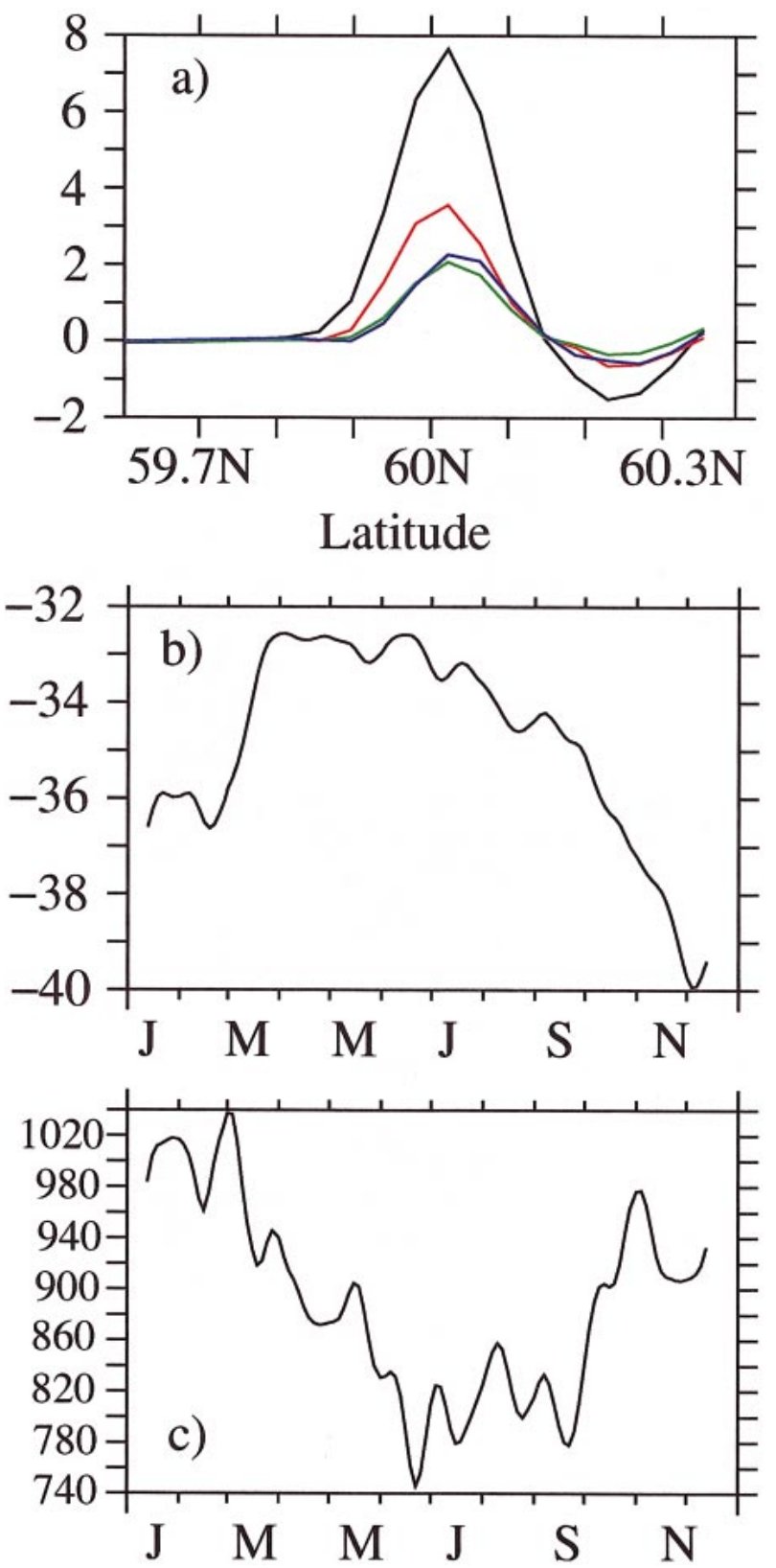

FIG. 13. (a) Seasonal averages of the transfer rate (vertically averaged from 100- to 400-m depth) from mean kinetic energy to eddy kinetic energy $\left(T_{4}\right.$, associated with barotropic instability of the mean flow) at $48^{\circ} \mathrm{W}$ (black, JFM; red, AMJ; green, JAS; and blue, OND. (b) The meridionally averaged $\left(59.6^{\circ}-60.4^{\circ} \mathrm{N}\right)$ zonal velocity (mean seasonal cycle) at $48^{\circ} \mathrm{W}$ in $100-\mathrm{m}$ depth $\left(\mathrm{cm} \mathrm{s}^{-1}\right)$. (c) The meridional variance $\left(\mathrm{cm}^{2} \mathrm{~s}^{-2}\right)$ of the average shown in (b) as an indicator for the seasonal cycle in EKE.

\section{b. Labrador Current}

While the seasonal cycle of EKE in the WGC appears sinusoidal to a first approximation, the seasonality in the LC differs in that the maximum in EKE occurs quite abruptly in late January. In the snapshots of the instantaneous near-surface velocity in January, shown in Fig.

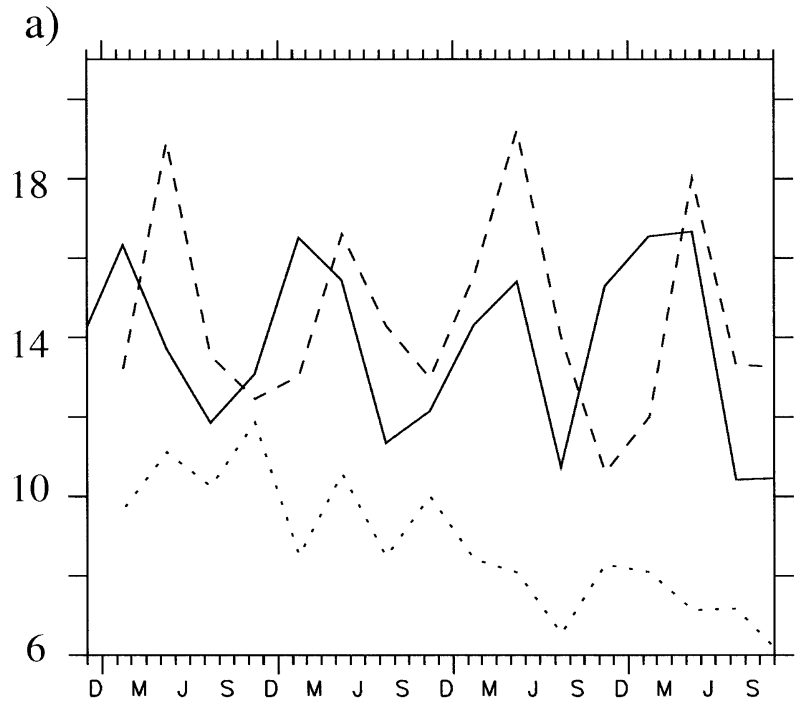

b)

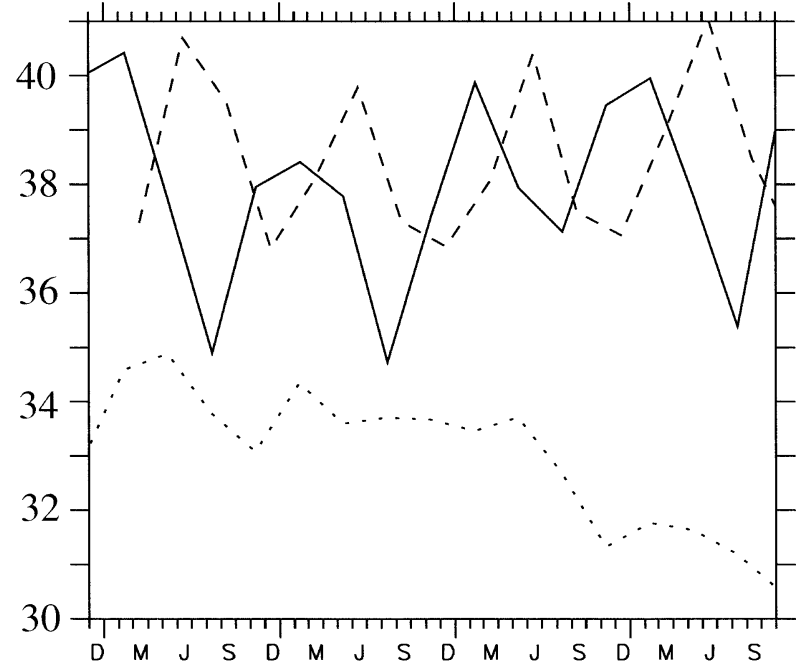

FIG. 14. (a) Near-surface EKE $\left(\mathrm{cm}^{2} \mathrm{~s}^{-2}\right)$ in the Labrador Sea in the $1 / 3^{\circ}$ model experiments: solid line denotes STANDARD-3, dashed line CONSTWIND-3, and the dotted line CONSTHEATWIND-3. (b) Vertically integrated transport (Sv) of the WGC near Cape Farewell (across $46^{\circ} \mathrm{W}$, north of $58.8^{\circ} \mathrm{N}$ ) for the same experiment.

8, small-scale fluctuations appear to arise nearly simultaneously along the entire $\mathrm{LC}$ at this time. According to Fig. 16c, EKE peaks value around mid-February, after a rapid increase during January.

In contrast to the WGC, baroclinic instability appears as the dominant source for the EKE maximum along the LC: $T_{4}$ is in general an order of magnitude smaller than $T_{2}$; further analysis will hence focus on the latter only. Figures $16 \mathrm{a}$ and $16 \mathrm{~b}$ show seasonal means of $T_{2}$ for the winter (JFM) and autumn seasons (OND). Maximum values of $T_{2}$ are reached in winter; this seasonal maximum in the mean flow instability appears to dominate the generation of eddies in the LC. Since the onset of the fluctuation along the LC occurs almost simulta- 
a)

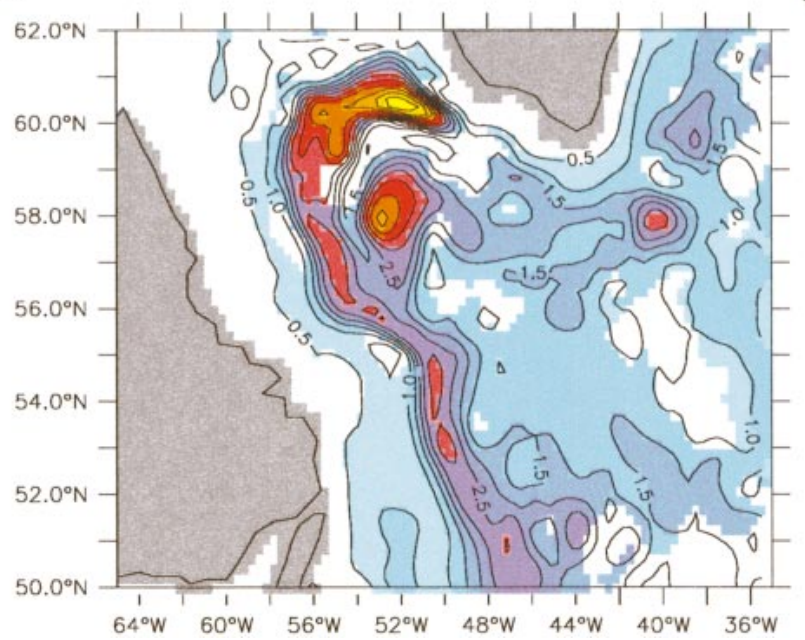

b)

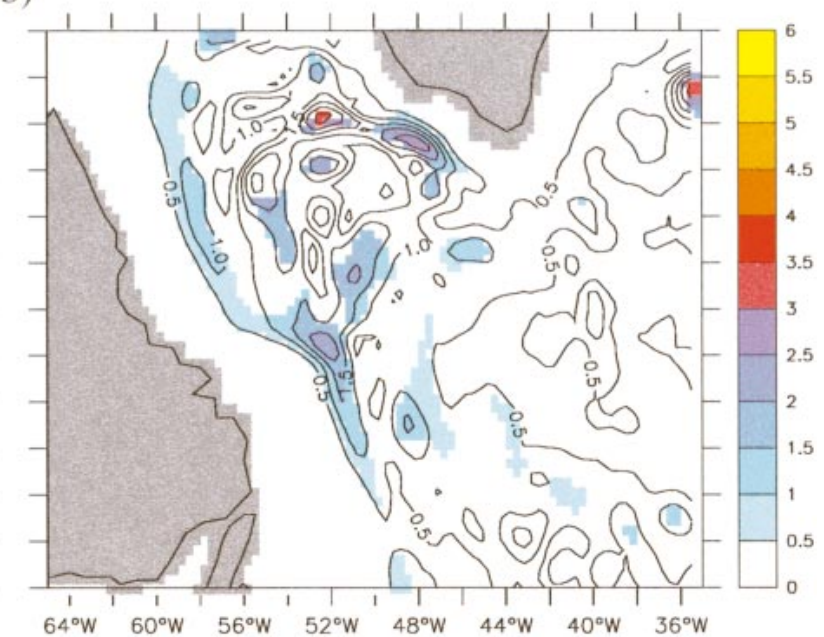

FIG. 15. (a) Root-mean-square of the annual march of the barotropic streamfunction (Sv) in STANDARD-3 and (b) CONSTWIND-3. Shading emphasizes the regions in which the variance of the seasonal cycle is larger than one-half of the variance of the anomalous variations, i.e., deviations from the mean seasonal cycle, as a measure of the signal-to-noise ratio.

neously along the entire current, downstream advection of EKE by the LC or from the interior Labrador Sea seems to play only a minor role. Time series of the mean gradients of the in situ density in the LC (not shown) suggests that the occurrence of the maximum crossstream gradient of the baroclinic structure coincides with the seasonal peak in EKE along the LC, and hence may be regarded as instrumental for the seasonality of the EKE.

The $1 / 3^{\circ}$ model does not show any enhanced EKE along the LC and so also no seasonality in it (not shown). Thus, the responsible mechanism should operate on spatial scales less than about $20 \mathrm{~km}$, which are not resolved by the $1 / 3^{\circ}$ model, also pointing toward a local baroclinic instability process. However, since the $1 / 3^{\circ}$ model does not show this signal, we are unable to determine the influence by either the wind stress forcing or the heat flux forcing on the fluctuations of the LC.

\section{Concluding discussion}

a. Summary

- The $1 / 12$ model simulation is in good agreement with observations regarding the mean boundary current structures in the Labrador Sea, as well as various properties of the eddy field: its spatial distribution, the annual mean amplitude and the seasonal cycle of EKE. A main feature is an energetic patch $\left(500 \mathrm{~cm}^{2} \mathrm{~s}^{-2}\right.$ or more) of eddy activity extending from the West Greenland coast near Cape Desolation into the interior Labrador Sea.

- Since the model was forced with monthly mean wind stresses, EKE generation is solely due to internal instability processes; it suggests that the observed sea- sonality in the EKE patch can be explained without invoking a direct eddy generation mechanism due to high frequency wind forcing.

- Inspection of the energy transfer terms points toward the importance of the Reynolds interaction work (barotropic instability) in the narrowing boundary current off Cape Desolation as the primary mechanism of eddy generation; the annual march of EKE can be attributed to a seasonal modulation of this energy transfer, due to a seasonally varying strength of the mean WGC.

- This result is confirmed by complementary experiments with the coarser $\left(1 / 3^{\circ}\right)$, "eddy-permitting" model, in which changes in the seasonality of the monthly mean surface forcing and, correspondingly, in the seasonality of the WGC, was determined as a leading factor for variations in EKE.

- A secondary maximum of EKE shows up along the LC. While the mean EKE is only weakly enhanced here (up to $150 \mathrm{~cm}^{2} \mathrm{~s}^{-2}$ ) it shows a pronounced seasonal cycle with amplitudes of about $100 \mathrm{~cm}^{2} \mathrm{~s}^{-2}$ and a peak in February, which can be attributed to a result of baroclinic instability.

- Eddies formed near the separation of the WGC off Greenland and propagating into the interior Labrador Sea are predominantly anticyclonic, with warm and saline (but lighter than the surrounding water) cores in the upper $1000 \mathrm{~m}$ of the water column. The few cyclonic eddies found in the model solution also seem to originate from the WGC; that is, the offshore flank, but have a more barotropic structure.

- The model solution suggests that the overwhelming dominance of the eddy activity in the interior Labrador Sea is due to eddies generated in the WGC; the ubiquity of these remotely forced eddies may effectively 
a)

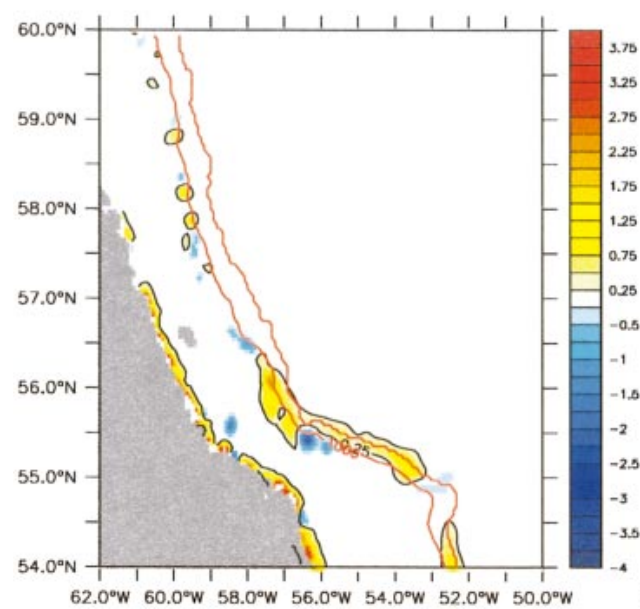

b)

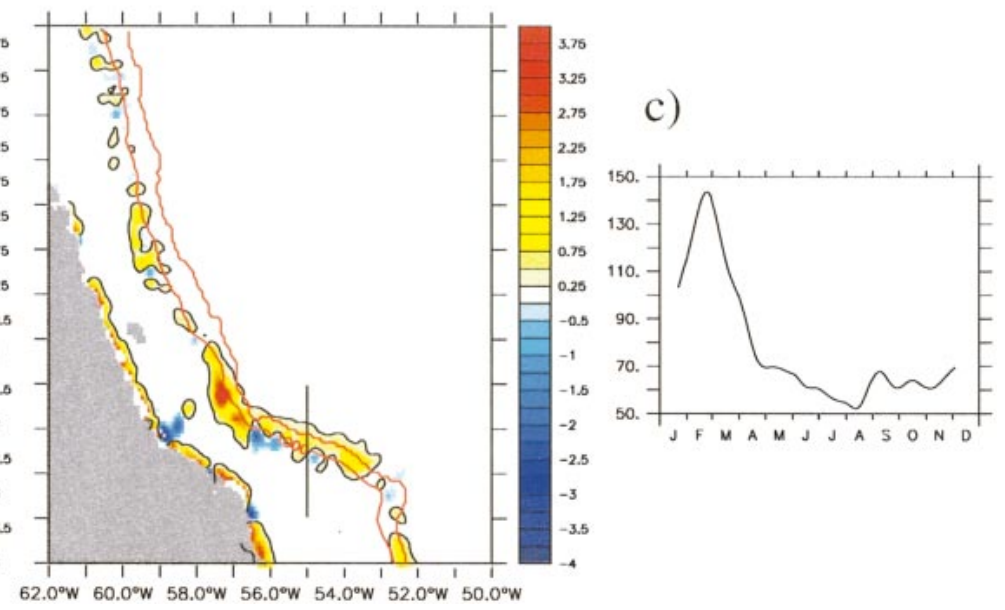

FIG. 16. (a),(b) The energy transfer rates from mean potential energy to eddy kinetic energy, vertically averaged from 100 - to 400 -m depth, in the Labrador Current (LC); units: $10^{-10} \mathrm{~m}^{2} \mathrm{~s}^{-3}$ for (a) autumn season (OND) and (b) winter season (JFM). Shaded are only regions in which the mean kinetic energy exceeds values of $300 \mathrm{~cm}^{2} \mathrm{~s}^{-2}$, which coincide roughly with the core of the deep branch of the LC. Contoured are the zero line for the transfer term (black) and the 1000- and the 2000-m isobaths (red). (c) The mean (3-yr mean) seasonal cycle of the meridional variance (filtered with a 1-month Hanning window) of the anomalies of the zonal velocity at $55^{\circ} \mathrm{W}$ in 100 - $\mathrm{m}$ depth as a proxy for the seasonal cycle in $\operatorname{EKE}\left(\mathrm{cm}^{2} \mathrm{~s}^{-2}\right)$. Note that this section is also denoted in (b).

mask a potential signal of "convective" eddies generated locally during or after phases of deep winter mixing. Moreover, the lateral eddy mixing important for the detrainment and restratification processes orchestrating the renewal of Labrador Sea Water may effectively be governed by the predominant variability associated with the "WGC eddies."

\section{b. Discussion}

The agreement of the model results with observations provides a good basis to investigate the sources and the role of this variability. The reproduction of the observed seasonal cycle in EKE by a model forced with monthly mean surface fluxes indirectly supports the conclusions of SBD that direct effects of synoptic wind variability are of very small amplitude, recognizable only in areas of very weak background EKE (i.e., EKE resulting from instability processes). Similar levels of EKE as in the present model (except for the moderate maximum in the LC, see below) were also obtained in the exp. by Smith et al. (2000), which included forcing by synoptic wind stress variability. The relation between changes in the (monthly mean) forcing, the strength of the WGC and the EKE in the present model solutions suggests that the apparent correlation between the EKE in the Labrador Sea and the high frequency (synoptic) variance of the wind field found by previous studies (White and Tai 1995; Stammer and Wunsch 1999) can be interpreted as an indirect impact of the mean annual cycle in the basin-wide wind stress curl and heat fluxes on the strength of the WGC.

While in most parts of the ocean and its boundary currents baroclinic instability appears to be the most important mechanism in generating mesoscale eddy activity (e.g., Beckmann et al. 1994), the present model results suggest barotropic instability of the WGC at its separation from Greenland's shelf near Cape Desolation as the main source of EKE in the Labrador Sea. We may, somewhat heuristically, argue that the dominance of energy transfer by Reynolds interaction work against the mean shear is related to the narrowing of the topographically guided WGC near Cape Desolation. There, the 1000- and 3000-m isobaths come as close as a couple of kilometers together; the induced increase in the vertical extent of the WGC, and corresponding decrease in width at this point, leads to locally strong horizontal shears sufficient for the occurrence of barotropic instability. Since this mechanism involves an intimate, local interaction of the boundary current with the topography at this point, it would appear interesting to test the robustness of this aspect of the present model solution by inspection of other high-resolution simulations, which might well differ in numerical details of the topography implementation.

The moderately enhanced EKE along the LC in our model results is not present in the experiment by Smith et al. (2000). It is also not obvious in the altimeter SSHA patterns (note, however, that this feature is also absent in the diagnosed SSHA from NON-VISCOUS-12). The use of different parameterizations for subgrid-scale mixing (harmonic versus biharmonic in the case of Smith et al. 2000) can apparently not explain this difference: Our preliminary $1 / 12{ }^{\circ}$ model experiment using biharmonic mixing (BIHARM-12) shows very similar results when compared with NON-VISCOUS-12 with respect 
to the amplitude of the EKE maximum in the WGC, the position of the subarctic front, and the moderate maximum in the LC. Which other model factors determine the different behavior of the $1 / 10^{\circ}$ case of Smith et al. (2000) in this regard remains an open question. Observational estimates of the EKE along the LC give no conclusive picture at this point. Altimeter data are usually regarded as not reliable enough near shelfs, because of possible deleterious effects of tidal signals. There are, however, regions of more than $100 \mathrm{~cm}^{2} \mathrm{~s}^{-2}$ along the shelf off the coast of Labrador in the maps of EKE as estimated from drifter data by Cuny et al. (2002) and BMS. It is also interesting to note that current meter data from a mooring array further downstream in the $\mathrm{LC}$, at about $52^{\circ} \mathrm{N}$, show enhanced variance around a 10-30-day frequency band, with a seasonal cycle similar to the present model results (F. Schott and J. Fischer 2001, personal communication), that is, with a rapid onset in January and a peak in late winter.

Recently, a census of potential eddy signals was obtained by LRS using a five-year-long time series of mooring data in the interior Labrador Sea. A main finding was a clearly dominant signal of anticyclonic eddies (31 of 33). The T/S characteristics of the eddy signals suggested their origins partly in the convection region in the interior (cold and fresh eddies) and in the WGC (warm and saline eddies). In contrast to theoretical and idealized numerical model studies (Send and Käse 2001, manuscript submitted to J. Phys. Oceanogr., hereafter SK) which predict equal numbers of cyclonic and anticyclonic eddies after convection, the observations gave no indication of cyclonic, (cold and fresh) "convectively" generated eddies. The present model is in agreement with the observations with respect to the predominance of anticyclonic eddies in the Labrador Sea (LRS); but in contrast to the observations it lacks a clear signal of cold and fresh "convectively" formed, anticyclonic eddies (we found only a few cold and fresh anticyclonic eddies in the model, anticyclones spawned from the WGC are predominantly warm and saline).

Process models simulating the generation of "rim current eddies" after (idealized) deep convection events use in general higher horizontal resolutions than $1 / 12^{\circ}$ (typically about $1 \mathrm{~km}$; e.g., SK). The present model configuration, while producing a deep patch of homogenized water in the interior Labrador Sea, which typically reaches $2500 \mathrm{~m}$ by the end of March, appears to still lack the resolution necessary to simulate this process. However, whether this possible additional source of eddy variability would be of much significance for the overall level of lateral mixing in the interior of the Labrador Sea appears somewhat in doubt at this point: Since the models simulates a realistic level of EKE due to eddies spawned from the WGC area alone, an additional contribution to the EKE due to "rim current eddies" would appear of minor importance.

The spreading of eddies from the WGC area into the area of deep wintertime convection, as evident from both observations and the model results, suggests a possible role of the instability processes in the boundary currents for the detrainment of newly formed Labrador Sea water and the restratification after convection. Since the model results show that this instability is controlled by the strength of the WGC, the Labrador Sea Water renewal rate and its interannual variation may to some degree be influenced by processes affecting the boundary currents; that is, changes in the wind stress curl over the subpolar North Atlantic and changes in the density structure which, via the bottom pressure torques, contribute also to changes in the subpolar gyre strength. Thus, the recently observed interannual changes in the EKE in the Labrador Sea (BMS) might be caused by changes in the strength of the WGC in response to changes in the wind stress curl forcing and/or changes in the density structure of the Labrador Sea.

Acknowledgments. This study was supported by the Deutsche Forschungsgemeinschaft, SFB 460. The model was developed as part of the FLAME Atlantic model hierarchy at IfM Kiel, and benefited greatly from contributions by J. Dengg, R. Redler, and K. Ketelsen. Comments by R. Smith and an anonymous reviewer helped to improve this manuscript. The experiments have been performed on parallel computer architectures (Cray T3E and Hitachi SR8000) at the German high performance computing centers in Berlin (ZIB) and Munich (LRZ).

\section{REFERENCES}

Barnier, B., L. Siefridt, and P. Marchesiello, 1995: Thermal forcing for a global ocean circulation model using a three year climatology of ECMWF analysis. J. Mar. Syst., 6, 363-380.

Beckmann, A., C. Böning, C. Köberle, and J. Willebrand, 1994: Effects of increased horizontal resolution in a simulation of the North Atlantic Ocean. J. Phys. Oceanogr., 24, 326-344.

Böning, C., and R. Budich, 1992: Eddy dynamics in a primitive equation model: Sensitivity to horizontal resolution and friction. J. Phys. Oceanogr., 22, 361-381.

Cheney, R., L. Miller, R. Agreen, N. Doyle, and J. Lillibridge, 1994: TOPEX/POSEIDON: The 2-cm solution. J. Geophys. Res., 99, 24 555-24 563.

Clarke, R. A., 1984: Transport through the Cape Farewell-Flemish Cap section. Rapp. P.-V. Reun. Cons. Int. Explor. Sci. Mer., 185, $120-130$.

, and J.-C. Gascard, 1983: The formation of Labrador Sea Water. Part I: Large-scale processes. J. Phys. Oceanogr., 13, 17641778.

Cummins, P., G. Holloway, and A. Gargett, 1990: Sensitivity of the GFDL ocean general circulation model to a parameterization of vertical diffusion. J. Phys. Oceanogr., 20, 817-830.

Cuny, J., P. Rhines, P. Niiler, and S. Bacon, 2002: Labrador Sea boundary currents and the fate of the Irminger Sea Water. $J$. Phys. Oceanogr., 32, 627-647.

Dengg, J., C. Böning, U. Ernst, R. Redler, and A. Beckmann, 1999: Effects of an improved model representation of overflow water on the subpolar North Atlantic. International WOCE Newsletter, No. 37, WOCE International Project Office, Southampton, United Kingdom, 10-15.

Dickson, R., W. Gould, P. Gurbutt, and P. Killworth, 1982: A seasonal signal in ocean currents to abyssal depths. Nature, 295, 193198.

Eden, C., and J. Willebrand, 2001: Mechanism of interannual to de- 
cadal variability of the North Atlantic circulation. J. Climate, 14, 2266-2280.

Esselborn, S., and C. Eden, 2001: Sea surface height changes in the North Atlantic Ocean related to the North Atlantic Oscillation. Geophys. Res. Lett., 28, 3473-3476.

Fischer, J., and F. Schott, 2002: Labrador Sea Water tracked by profiling floats-From the boundary current into the open North Atlantic. J. Phys. Oceanogr., 32, 573-584.

Frankignoul, C., and P. Müller, 1979: Quasigeostrophic response of an infinite beta-plane ocean to stochastic forcing by the atmosphere. J. Phys. Oceanogr., 9, 104-127.

Fratantoni, D., 2001: North Atlantic surface circulation during the 1990's observed with satellite-tracked drifters. J. Geophys. Res., 106, 22 067-22 093.

Gargett, A., 1984: Vertical eddy diffusivity in the ocean interior. $J$. Mar. Res., 42, 359-393.

Gerdes, R., and C. Köberle, 1995: On the influence of DSOW in a numerical model of the North Atlantic general circulation. $J$. Phys. Oceanogr., 25, 2624-2642.

Greatbatch, R. J., and A. Goulding, 1989: Seasonal variations in a linear barotropic model of the North Atlantic driven by the Hellerman and Rosenstein wind stress field. J. Phys. Oceanogr., 19, 572-595.

Häkkinen, S., 1999: A simulation of thermohaline effects of a great salinity anomaly. J. Climate, 12, 1781-1795.

Harrison, D., and A. Robinson, 1978: Energy analysis of open regions of turbulent flows: Mean eddy energetics of a numerical ocean circulation experiment. Dyn. Atmos. Oceans, 2, 185-211.

Koblinsky, C., P. Niiler, and W. Schmitz, 1989: Observations of windforced deep-ocean currents in the North Pacific. J. Geophys. Res. 94, $10773-10790$.

Lazier, J., 1973: The renewal of Labrador Sea Water. Deep-Sea Res., 20, 341-353.

— Current. J. Phys. Oceanogr., 23, 659-678.

Lorenz, E., 1955: Available potential energy and the maintenance of the general circulation. Tellus, 7, 157-167.

Marshall, J., and F. Schott, 1999: Open-ocean convection: Observations, theory, and models. Rev. Geophys., 37, 1-64.

Müller, P., and C. Frankignoul, 1981: Direct atmospheric forcing of geostrophic eddies. J. Phys. Oceanogr., 11, 287-308.

Oschlies, A., 2002: Improved representation of upper-ocean dynamics and mixed layer depths in a model of the North Atlantic on switching from eddy-permitting to eddy-resolving grid resolution. J. Phys. Oceanogr., 32, 2277-2298.

Pacanowski, R., 1995: MOM 2 documentation, user's guide and ref- erence manual. Tech. Rep., GFDL Ocean Group, Geophysical Fluid Dynamics Laboratory, Princeton, NJ, 329 pp.

Paiva, A., J. Hargrove, E. Chassignet, and R. Bleck, 1999: Turbulent behavior of a fine mesh (1/12 degree) numerical simulation of the North Atlantic. J. Mar. Syst., 21, 307-320.

Prater, M., 2002: Eddies in the Labrador Sea as observed by profiling RAFOS floats and remote sensing. J. Phys. Oceanogr., 32, 411427.

Redler, R., K. Ketelsen, J. Dengg, and Böning, 1998: A high-resolution model for the circulation of the Atlantic Ocean. Proc. Fourth European SGI/CRAY MPP Workshop, Garching, Germany, Max-Planck-Institut für Plasmaphysik, 95-108.

Reverdin, G., N. Verbrugge, and H. Valdimarson, 1999: Upper ocean variability between Iceland and Newfoundland 1993-1998. J. Geophys. Res., 104 (C12), 29 599-29 611.

Reynauld, T., A. Weaver, and R. Greatbatch, 1995: Summer mean circulation of the northwestern Atlantic Ocean. J. Geophys. Res., 100, 779-816.

Smith, R., M. Maltrud, F. Bryan, and M. Hecht, 2000: Numerical simulation of the North Atlantic Ocean at $1 / 10^{\circ}$. J. Phys. Oceanogr., 30, 1532-1561.

Smith, W., and D. Sandwell, 1997: Global seafloor topography from satellite altimetry and ship depth soundings. Science, 277, 19571962.

Stammer, D., 1997: Steric and wind-induced changes in TOPEX/ POSEIDON large-scale sea surface topography observations. $J$. Geophys. Res., 102, 20 987-21009.

—_ and C. Wunsch, 1999: Temporal changes in eddy energy of the oceans. Deep-Sea Res., 46B, 77-108.

— C. C. Böning, and C. Dieterich, 2001: The role of variable wind forcing in generating eddy energy in the North Atlantic. Progress in Oceanography, Vol. 48, Pergamon, 289-312.

Treguier, A., 1992: Kinetic energy analysis of an eddy resolving, primitive equation model of the North Atlantic. J. Geophys. Res., 97 (C1), 687-701.

White, M., and K. Heywood, 1995: Seasonal and interannual changes in the North Atlantic subpolar gyre from Geosat and TOPEX/ POSEIDON altimetry. J. Geophys. Res., 100 (C12), 24 931-24 941.

White, W., and C.-K. Tai, 1995: Inferring interannual changes in global upper ocean heat storage from TOPEX altimetry. J. Geophys. Res., 100, 24 943-24 954.

Willebrand, J., S. Philander, and R. Pacanowski, 1980: The oceanic response to large-scale atmospheric disturbances. J. Phys. Oceanogr., 10, 411-429.

- and Coauthors, 2001: Circulation characteristics in three eddypermitting models of the North Atlantic. Progress in Oceanography, Vol. 48, Pergamon, 123-161. 